Article

\title{
Green Synthesis of Silver Nanoparticles and Evaluation of Their Antibacterial Activity against Multidrug-Resistant Bacteria and Wound Healing Efficacy Using a Murine Model
}

\author{
Vajravathi Lakkim ${ }^{1}{ }^{1}$, Madhava C. Reddy ${ }^{2}{ }^{\oplus}$, Roja Rani Pallavali ${ }^{2} \mathbb{D}$, Kakarla Raghava Reddy $^{3}$, \\ Ch Venkata Reddy ${ }^{4, *}$, Inamuddin ${ }^{5}$, Anwar L. Bilgrami ${ }^{6}(\mathbb{D})$ and Dakshayani Lomada ${ }^{1, *}$ \\ 1 Department of Genetics and Genomics, Yogi Vemana University, Kadapa, AP 516005, India; \\ vajravathi@gmail.com \\ 2 Department of Biotechnology and Bioinformatics, Yogi Vemana University, Kadapa, AP 516005, India; \\ cmreddy@yogivemanauniversity.ac.in (M.C.R.); p.rojarani.virology@gmail.com (R.R.P.) \\ 3 School of Chemical and Biomolecular Engineering, The University of Sydney, Sydney, NSW 2006, Australia; \\ raghava.kakarla@sydney.edu.au \\ 4 School of Mechanical Engineering, Yeungnam University, Gyeongsan 712-749, Korea \\ 5 Advanced Functional Materials Laboratory, Department of Applied Chemistry, Zakir Husain College of \\ Engineering and Technology, Faculty of Engineering and Technology, Aligarh Muslim University, \\ Aligarh, UP 202002, India; inamuddin@zhcet.ac.in \\ 6 Deanship of Scientific Research, King Abdulaziz University, Jeddah 80216, Saudi Arabia; \\ alegman@kau.edu.sa \\ * Correspondence: cvreddy@ynu.ac.kr (C.V.R.); dlomada@yogivemanauniversity.ac.in (D.L.); \\ Tel.: +91-9652001184 (D.L.)
}

Received: 2 November 2020; Accepted: 10 December 2020; Published: 13 December 2020

\begin{abstract}
Green nanotechnology has significant applications in various biomedical science fields. In this study, green-synthesized silver nanoparticles, prepared by using Catharanthus roseus and Azadirachta indica extracts, were characterized using UV-Vis spectroscopy, dynamic light scattering, X-ray diffraction, scanning electron microscopy, and transmission electron microscopy. Silver nanoparticles (Ag NPs) synthesized from leaf extracts of C. roseus and A. indica effectively inhibited the growth of multidrug-resistant (MDR) bacteria isolated from patients with septic wound infections. The maximum bacteriolytic activity of the green-synthesized Ag NPs of C. roseus and A. indica against the MDR bacterium K. Pneumoniae was shown by a zone of inhibition of 19 and $16 \mathrm{~mm}$, respectively. C. roseus Ag NPs exhibited more bacteriolytic activity than A. indica Ag NPs in terms of the zone of inhibition. Moreover, these particles were effective in healing wounds in BALB/c mice. Ag NPs of $C$. roseus and $A$. indica enhanced wound healing by $94 \% \pm 1 \%$ and $87 \% \pm 1 \%$, respectively. Our data suggest that Ag NPs from C. roseus and A. indicia ameliorate excision wounds, and wound healing could be due to their effective antimicrobial activity against MDR bacteria. Hence, these Ag NPs could be potential therapeutic agents for the treatment of wounds.
\end{abstract}

Keywords: silver nanoparticles; green synthesis method; Catharanthus roseus; Azadirachta indica; multidrug-resistant bacteria; wound healing

\section{Introduction}

Burn injuries, wounds, and diabetic foot ulcers (DFUs) are global public health problems and a leading cause of mortality and amputations. The healing of burns, wounds, and DFUs involves a dynamic and complex network that requires continuous communication between cells in the form of 
cytokine release, cell-to-cell contacts, and cell-to-matrix interactions. The use of nanomedicines has increased enormously, and nanomaterials have been shown to offer promising strategies to optimize and improve the treatment of numerous disorders, including burns and wounds, owing to their unique small size, large surface area, and large surface-to-volume ratio. Hence, nanoparticles are considered magic bullets that are used in fundamental tasks in science, medicine, and different biotechnological fields, including imaging, biosensors, targeted drug delivery, and disease therapy [1,2]. More importantly, nanoparticles have played a role in delivering drugs, light, heat, and many substances to specific cancer cells in several biological applications. Metal nanoparticles are eminently illustrated as having antioxidant, anticancer, anti-inflammatory, and antimicrobial activities and play a role in wound healing [3-5]. Prior to antibiotic discovery, silver( $\mathrm{Ag})$ was widely used as an antimicrobial agent to treat wound infections [6].However, after the discovery and abundant application of antibiotics, silver usage subsided because of its toxic nature and the easy applicability of antibiotics. Researchers have gained interest in using silver nanoparticles (Ag NPs) coupled with phytochemicals for use as antibacterial, antifungal, and anticancer agents [7].

Green synthesis of nanoparticles has gained attention because of its advantages, including being nontoxic, safe for humans, eco-friendly, and economically viable, compared to chemical and physical synthesis methods [8]. Instead of using silver alone, Ag NPs coupled with phytoextracts have gained more interest because of their action on bacterial and fungal pathogens and promotion of wound healing. Green-synthesized Ag NPs have been extensively used in biomedicine, purification of water, cosmetics, the food industry, numerous household products, and clothing $[9,10]$. Using plant extracts, Ag NPs synthesis has recently advanced, and it is now safe, allows convenient collection, and can utilize a wide range of metabolites for promoting the bioreduction of $\mathrm{Ag}^{+}$(silver ions). Jha et al. demonstrated that plant leaf chemical constituents are precisely implicated in the lessening of silver ions and the formation of silver nanoparticles [11]. It has been shown that Ag NPs and crude phytoextracts successfully inhibit multidrug-resistant (MDR) bacterial growth [12-15]. The antifungal capacity of green-synthesized Ag NPs has gained only marginal attention from researchers in the field of plant pathology $[2,16]$. Biological methods implicated in Ag NPs synthesis utilize natural plant leaf extracts that act as both reductants and capping agents [17,18].

In folk medicine, Catharanthus roseus (C. roseus; also known as "Sadabahar" or "Madagascar periwinkle"), which belongs to the "Apocynaceae" family, is widely known as a significant medicinal plant that is used for the treatment of many maladies [19]. C. roseus leaves and roots are a source of fundamental anticancer drugs such as vincristine and vinblastine; its phytochemicals, including alkaloids, have been shown to have antihypertensive and anticancer effects [20]. Native to the Indian subcontinent, Azadirachta indica (A. indica) is another medicinal plant belonging to the "Meliaceae" family; it is typically grown in tropical and subtropical regions. A. indica is an abundant source of triterpenoid phytochemicals, like limonoids, that are enriched with powerful medicinal properties, including anti-inflammatory, antioxidant, anticancer, and anti-helminthic activities, as well as natural insecticidal activities [21]. A. indica leaves, cork, seeds, and oil are widely used in healthcare products and in Sidda, Unani, and Ayurveda medicine.

To control bacterial infections of septic wounds, many conventional antibiotics have been tested by researchers to maintain sterile conditions on wounds and possibly enhance their healing rate. However, due to the overconsumption of antibiotics, mutations in DNA, transposons, and R-plasmids of bacteria may result in the development of drug resistance [22]. Prolonged antibiotic administration may inhibit the growth of natural flora and also affect the synthesis of various biomolecules such as growth factors and cytokines. Worldwide, even in developed nations, skin infections due to microbes are the cause of approximately $42-65 \%$ of total skin-related morbidity, occurring particularly among children [23]. Ansari et al. demonstrated that microbial species such as Staphylococcus aureus were frequently colonized on human skin and wounds can cause several types of infections on the skin [24]. S. aureus infections on the skin's soft tissue can spread intothe surroundings, causingsevere 
diseases such as bacteremia [25]. Silver nanoparticles promote the production of free oxygen radicals, which oxidize the bacterial molecular structure through the delivery of silver $\left(\mathrm{Ag}^{+}\right)$ions [26].

Biosynthesized Ag NPs have distinct advantages in medical fields, act as antimicrobials, and are used for drug delivery $[27,28]$. Because of their size advantage $(7-20 \mathrm{~nm})$, Ag NPs act as drug carriers that inhibit the growth of microbes and detoxify most microbial contaminations by disrupting cell membranes and blocking various biological molecules [29]. Biosynthesized Ag NPs are widely utilized as antibacterial components against several MDR bacteria and also reduce the development of antibiotic resistance. Because of their small size, biosynthesized Ag NPs accumulate on the cellular membranes of bacteria and cause an imbalance in microbial membrane integrity, leading to the death of the targeted bacteria, irrespective of their drug-resistant nature [30]. The mechanism of activity of biosynthesized Ag NPs is not completely understood; the significant general approaches of their activity are as follows:

- Biosynthesized Ag NPs release free silver ions that traverse into cells, causing further breakdown of adenosine triphosphate (ATP) generation and promotingthe replication of DNA.

- $\quad \mathrm{Ag} \mathrm{NPs}$, along with $\mathrm{Ag}^{+}$ions, enhance the production of reactive oxygen species (ROS) in an antioxidant mechanism.

- Ag NPs cause cell membrane damage directly.

Commonly described mechanisms begin with silver ion release [31], followed by ROS generation $[13,32]$ and cell membrane damage, but many ambiguous findings have been reported. Generally, the metal form of silver $(\mathrm{Ag})$ nanocrystallites represents an optical peak at $3 \mathrm{KeV}$ because of their surface plasmon resonance [33].

The current study is mainly focused on the green synthesis of Ag NPs from leaf extracts of $C$. roseus and A. indica and the characterization of their morphological and structural properties. Antibacterial efficacy of the characterized nanoparticles was evaluated using the isolates of septic wound infections, such as MDR Escherichia coli, Klebsiella pneumoniae, Staphylococcus aureus, and Pseudomonas aeruginosa. The wound-healing efficacy of $\mathrm{Ag} \mathrm{NPs}$ of $C$. roseus and $A$. indica was determined by using in-vivo studies on BALB/c mice through wound excision models. Green-synthesized Ag NPs were produced without using any toxic chemicals or physical approaches and required a low concentration of leaf extract. The method we used to synthesize Ag NPs is easy, inexpensive, and simple to implement. Currently, there is an improved awareness of green synthesis as eco-friendly, stable, safe, and economical, and successful antimicrobial agents have a wide range of applications in healthcare products [34]. Phyto-derived Ag NPs are an especially important resource in the medical research field [35]. We synthesized Ag NPs from aqueous leaf extracts of $C$. roseus and A. indica; then, we characterized them via X-ray diffraction (XRD), Fourier-transform infrared spectroscopy (FT-IR), dynamic light scattering (DLS), scanning electron microscopy (SEM) with energy dispersive X-ray analysis (SEM-EDX), and transmission electron microscopy (TEM) analyses; finally, we showed their antibacterial efficacy against MDR bacteria and wound healing capacity using an animal model.

\section{Results and Discussion}

\subsection{Bioreduction and Synthesis of $A g N P S$}

Ag NPs were synthesized from C. roseus (C Ag NPs) and A. indica (A Ag NPs) leaf extracts; the development of a brownish color was observed immediately after adding phytoextracts to $1 \mathrm{mM}$ silver nitrate $\left(\mathrm{AgNO}_{3}\right)$ due to the bioreduction of silver $\left(\mathrm{Ag}^{+}\right)$ions into silver nanoparticles $(\mathrm{Ag} \mathrm{NPs})$. Different concentrations (1to $5 \mathrm{mM}$ ) of $\mathrm{AgNO}_{3}$ with phytoextracts exhibited the appearance of a dark brown color, confirming the formation of Ag NPs, as shown in Figure 1A. The development of color was enhanced with time because of $\mathrm{Ag}^{+}$reduction. During the synthesis of Ag NPs, due to the presence of biomass in the reaction mixture, the color changed from yellow-brown to darkish-brown. Here, biomass plays an essential role in the biosynthesis of Ag NPs. According to Mulvaney, the color change in the suspensions is due to the Ag NPs excitation of surface plasmonresonance vibrations [35]. 
Phytochemicals such as alkaloids, phenolic compounds, terpenoids, enzyme proteins, coenzymes, and sugars reduce metal (Ag) salts from a positive-oxidation state to a zero-oxidation state. The size and size distribution of metallic silver nanoparticles significantly depend on the biocompounds present in the extract. The presence of a strong reductantin the leaf extract enhances the bioreduction rate and favors the formation of smaller nanoparticles.
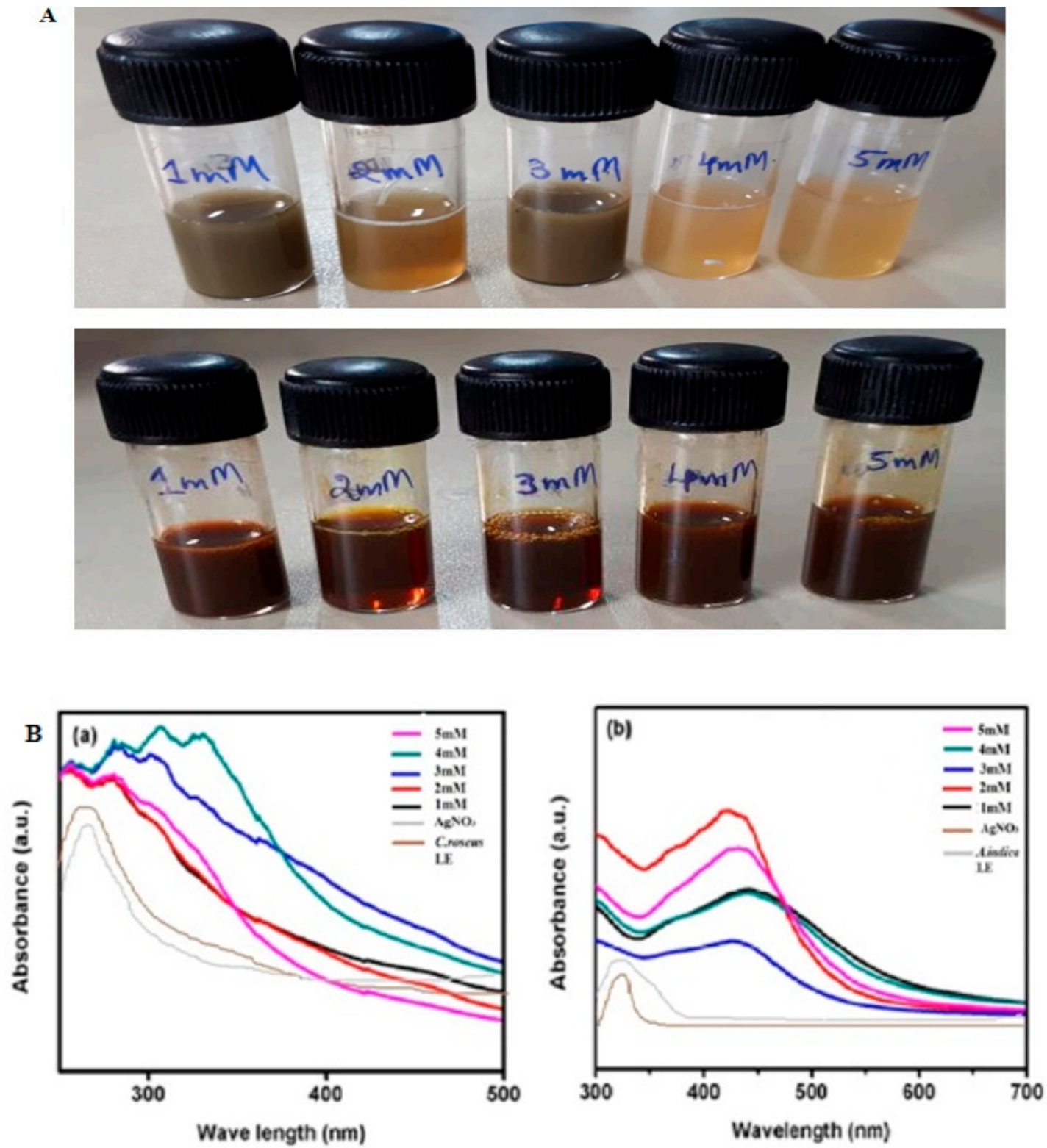

Figure 1. (A) Bioreduction of silver nanoparticles from Catharanthus roseus (top panel) and Azadirachta indica (bottom panel) leaf extracts. (B) UV-Vis spectroscopy analysis of biosynthesized silver nanoparticles of Catharanthus roseus (a) and Azadirachta indica (b) plant leaf extracts.

\subsection{UV-Vis Spectra Analysis of Ag NPs}

The structural characterization of green-synthesized nanoparticles was performed by UV-Vis spectral analysis. Mixing C. roseus and A. indica leaf extract suspensions with 1 to $5 \mathrm{mM} \mathrm{AgNO} 3$ changed the color from light yellow-brown to dark brown, as mentioned above Figure 1A. As the reaction progressed, the color transformation revealed a reduction of $\mathrm{Ag}^{+}$from silver nitrate to nanosilver, which was detected by the absorption maxima peak in the range of 300 to $500 \mathrm{~nm}$. The samples were observed periodically in the $\mathrm{UV}-\mathrm{Vis}$ spectrometer at various concentrations of $\mathrm{AgNO}_{3}(1$ to 
$5 \mathrm{mM}$ ), along with $\mathrm{AgNO}_{3}$ alone and phytoextracts without the addition of $\mathrm{AgNO}_{3}$. At the same time, the samples were monitored by UV-Vis spectroscopy, which revealed a sharp peak at 315-360 nm in C. roseus and at $410-440 \mathrm{~nm}$ in A. indica, as shown in Figure 1B. These data confirmed the formation of Ag NPs from the phytoextracts. We did not observe an increase in absorbance with increasing concentrations of $\mathrm{AgNO}_{3}$ with $\mathrm{C}$ Ag NPs. The lack of dependence on increasing concentration in $\mathrm{C}$ Ag NPs may be due to their particle size formation during the synthesis of Ag NPs from C. roseus phytoextract with $\mathrm{AgNO}_{3}$. This may be because an increase in concentration increases the density of nanoparticles. Furthermore, the surface plasmonresonance (SPR) peak gradually shifted towards red with respect to the concentration. The shift towards red indicates that the particle size gradually increases with concentration. Curve sharpness also increased with concentration, which may be due to the formation of spherical and cubical nanoparticles. This is illustrated in the UV-Vis spectra through the rise in absorbance and shift of the SPR peaks [36-38]. In biologically synthesized nanoparticles, there was a considerable shift in the absorption maxima. Narayan et al. showed that the free electrons in metal nanoparticles allowed the SPR absorption band in the UV-Vis spectrum [7]. Such a characteristic change in color was due to the excitation of SPR in the metal nanoparticles of the plant leaf extracts that reacted with the $1 \mathrm{mM}$ silver nitrate $\left(\mathrm{AgNO}_{3}\right)$ suspension. The UV-Vis spectra of the reaction mixture, at a range of wavelengths varying within 300-600 nm, showed a sharp peak at 320-335 and 420-440 nm in C. roseus and A. indica, respectively [36,37]. According to Udayasoorian et al., a sharp absorption band illustrates a spherical shape, and two other SPR bands are related to anisotropic particles [38]. According to Wiley et al., this method was used to investigate the shape and size of nanoparticles in liquid solutions [39].Hence, the UV-Vis spectroscopic findings verified that $C$. roseus and $A$. indica phytoextracts reduce silver-to-silver nanoparticles (Ag NPs). Bhakya and coworkers observed that peaks exploit the cubic structure and crystalline properties of biosynthesized silver nanoparticles in nanoscale units [40].

\subsection{X-ray Diffraction Studies}

The crystalline nature of the green-synthesized Ag NPs from plant leaf extracts demonstrated that specific peaks were observed in the spectra analysis using the X-ray diffraction (XRD) method (Rigaku, Miniflex). The Ag NPs X-ray diffraction spectrum demonstrated sharp scattering peaks at $2 \theta=27.9^{\circ}, 32.2^{\circ}, 34.6^{\circ}, 38.4^{\circ}, 44.2^{\circ}, 57.8^{\circ}, 64.7^{\circ}$, and $77.4^{\circ}$, corresponding to the (210), (113), (200), (111), (124), (240), (226), and (300) planes of the face-centered cubic crystal structure for silver (Ag), as depicted in Figure 2A. Four Bragg's reflection patterns at $2 \theta=32.2^{\circ}, 38.4^{\circ}, 44.2^{\circ}$, and $64.7^{\circ}$ and in the spectrum varying in the range of 10-90 are represented by the conventional XRD method. The XRD spectrum patterns were considerably associated with (113), (111), (124), and (240). The lattice planes in the XRD spectrum were confirmed and crosschecked with the standard referral peak values (JCPDS Files no. 84-0173 and 04-0783), demonstrating that the synthesized Ag NPs were crystalline. The XRD spectra showed that the $C$. roseus and A. indica leaf extracts produced Ag NPs, and their crystalline nature was confirmed through the XRD method. The XRD peaks of the green-synthesized Ag NPs, with reference values, showed that Ag NPs were produced. The formed nanoparticles were confirmed via sharp peaks, and their $2 \theta$ values were $27.9^{\circ}, 32.2^{\circ}, 34.6^{\circ}, 38.4^{\circ}, 44.2^{\circ}, 57.8^{\circ}, 64.7^{\circ}$, and $77.4^{\circ}$, corresponding to (210), (113), (200), (111), (124), (240), (226), and (300), respectively, for Ag. Our XRD results demonstrated that the Ag NPs produced through the reduction of silver $\left(\mathrm{Ag}^{+}\right)$ions with $C$. roseus and A. indica extracts were crystalline in nature. Our data are consistent with earlier reports [41,42]. Unidentified peaks (peaks $27.9^{\circ}, 34.6^{\circ}$, and $57.9^{\circ}$ ) were observed, and it was recognized that the phytochemicals acted as capping agents for Ag NPs production [43]. In addition, Ag NPs (around $20 \mathrm{~nm}$ ) with a face-centered crystalline cubic structure were confirmed. Shameli et al. demonstrated that the XRD pattern of Ag NPs showed a crystalline property in cubic form [44]. Bhakya and coworkers observed that peaks indicate a cubic structure and the crystalline properties of biosynthesized Ag NPs in nanoscale units [40]. 

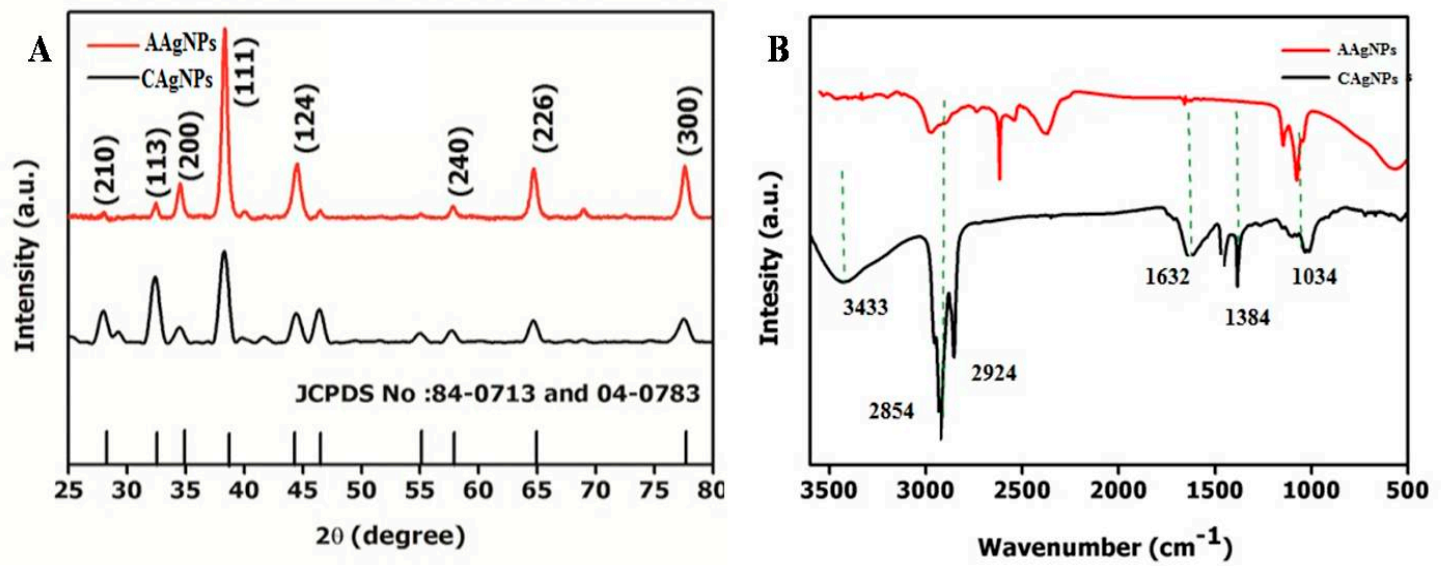

Figure 2. (A) X-ray diffraction (XRD) analysis of Catharanthus roseus silver nanoparticles (C Ag NPs) and Azadirachta indica silver nanoparticles (A Ag NPs).(B) FTIR spectra of Catharanthus roseus silver nanoparticles (C Ag NPs) and Azadirachta indica silver nanoparticles (A Ag NPs).

\subsection{FTIR Analysis}

A conventional Fourier transform infrared (FTIR) approach was used to identify secondary metabolites involved in reducing and capping for the synthesis of Ag NPs. FTIR spectra were recorded by employing potassium bromide (KBr) disks using an FTIR spectrometer (Perkin Elmer, Spectrum 2) with a wavenumber of 4000 to $400 \mathrm{~cm}^{-1}$. The characteristic FTIR spectrum of green-synthesized Ag NPs, as depicted in Figure 2B, showed peaks at 3433, 2854, 2924, 1632, 1384, and $1034 \mathrm{~cm}^{-1}$. In this spectrum, a sharp absorption signal peak at $3433 \mathrm{~cm}^{-1}$ is related to the $\mathrm{N}-\mathrm{H}$ bond of amine groups of green-synthesized Ag NPs and provides stabilization of Ag NPs. Hence, the occurrence of N-H group-specific proteins and enzymes correspond to the reduction of $\mathrm{AgNO}_{3}$ to $\mathrm{Ag}$ [32]. A comparative study of the FTIR spectrum ofthe control shows the most important signal peaks of $\sim 3433,1632$, and $1384 \mathrm{~cm}^{-1}$, illustrating the N-H group's presence on the surface of Ag NPs. According to Mishra et al., the cell-free extract might contain biomolecules such as peptides and proteins that affect the formation of Ag NPs through reduction [45].

The wide peak at $3433 \mathrm{~cm}^{-1}$ demonstratesan amide $(\mathrm{N}-\mathrm{H})$ stretching vibration of the $\mathrm{NH}_{2}$ group, and $\mathrm{OH}$ with overlapping stretching vibration for water is recognized in A. indica. FTIR visible peaks with $\mathrm{N}-\mathrm{H}$ and $\mathrm{OH}$ bond stretching at $3433 \mathrm{~cm}^{-1}$ clearly illustratesthe functional groups present in the green-synthesized C. roseus and A. indica Ag NPs, as shown individually in Appendix A and Figure A1. Another peak at $1632 \mathrm{~cm}^{-1}$ belongs to the stretching of $C=O$ and a sharp signal peak at $2854 \mathrm{~cm}^{-1}$ could berelatedto the alkyne group in the leaf extracts of $C$. roseus and $A$. indica. The visible sharp signals at $1384 \mathrm{~cm}^{-1}$ represent $\mathrm{C}-\mathrm{O}-\mathrm{C}$ and $\mathrm{C}-\mathrm{O}$ bonds. These visible signals are mainly related to flavonoids and terpenoids specifically present in plant extracts of $C$. roseus and $A$. indica $[46,47]$. These findings are in agreement with existing literature and confirmed that many bioorganic constituents from $C$. roseus and A. indica extracts produced persistent capping agents on green-synthesized Ag NPs [48].

\subsection{Dynamic Light Scattering}

We measured the distribution, typical particle size, and polydispersity index (PDI) of green-synthesized Ag NPs using dynamic light scattering (DLS).DLS data illustrated that the Ag NPs produced by the green route had a 31.4 diameter with $\mathrm{Z}$, as reported by the distributions of size in number percentage. Briefly, $20.5 \mathrm{~nm}$ is related to $\mathrm{q}^{\mathrm{O}}$ (number density distribution) and is based on the number percentage correlated with a polydispersity index of 0.65 , demonstrating that the green-synthesized Ag NPs were greatly diffusive in suspensions (Figure 3). Using this approach, it was found that the nanoparticles hydrodynamic diameter was greater than the original diameter obtained from SEM and TEM images. Hence, due to electrostatic repulsions of the green-synthesized Ag NPs, the zeta potential value -15.2 represents great stability in water. The bioorganic constituents in the 
suspension serve as spacers to avoid agglomeration between Ag NPs. The TEM images assist the steric stabilization process, and the DLS study showed that Ag NPs biosynthesized through the green route resulted in a $35.69 \mathrm{~nm}$ average diameter. A polydispersity index (PDI) of 0.56 demonstrated that the green-synthesized Ag NPs were widely dispersed in a liquid medium. In DLS, the average particle size of C Ag NPs was $110 \mathrm{~nm}$, with a range of 80-250 nm, and the average particle size of A Ag NPs was $60 \mathrm{~nm}$, with various ranges of $40-80 \mathrm{~nm}$, as indicated in Figure A2.
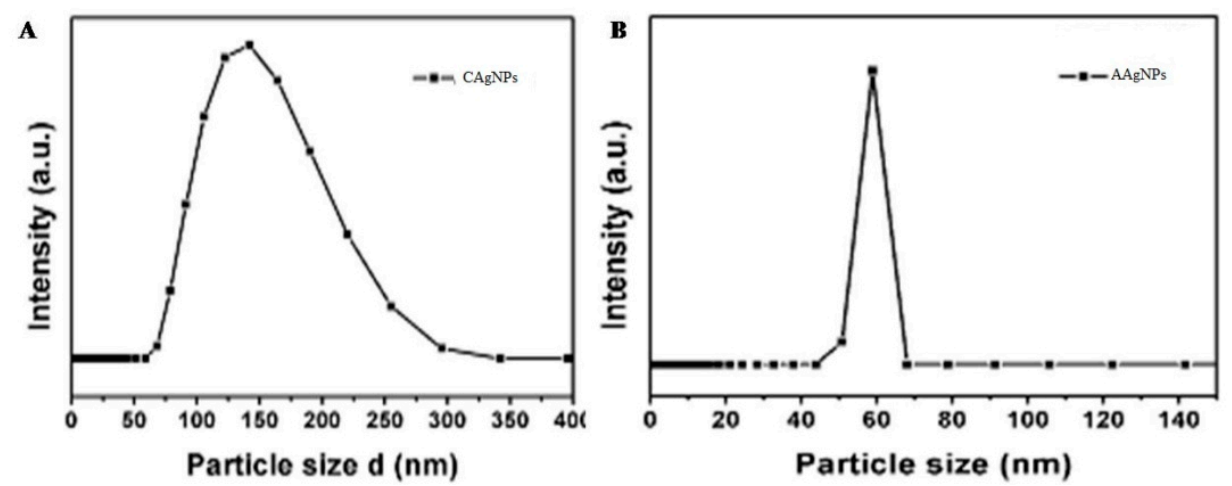

Figure 3. The hydrodynamic size determination of green-synthesized Ag NPs of Catharanthus roseus (A) and Azadirachta indica (B) by dynamic light scattering (DLS).

\subsection{Scanning Electron Microscopy}

The morphology of the green-synthesized Ag NPs was analyzed by scanning electron microscopy [49], and the pictures showthe cubic structure and unique shape of the nanoparticles produced with a 48-67 nm diameter range.

Analysis by the energy-dispersive X-ray (EDX) spectrum revealed that the incidence of silver elemental signals confirmed that the formed particles were Ag NPs through the bioreduction mechanism of leaf extracts with $\mathrm{AgNO}_{3}$. The $y$-axis represents the number of X-ray counts, and the $x$-axis represents energy in keV. The sharp elemental signal peaks showed the most significant emission energies for Ag, and these lines in the EDX spectrum confirmed that Ag had been properly recognized.

The silver peak was from Ag NPs, and its atomic percentage was 13.1\% in C. roseus and 19.9\% in A. indica, as shown in Figures 4 and 5, respectively. In C. roseus, except for Ag, the atomic percentages of carbon $(\mathrm{C})$, chlorine $(\mathrm{Cl})$, oxygen $(\mathrm{O})$, and aluminum $(\mathrm{Al})$ were $48.5 \%, 30 \%, 6.7 \%$, and $0.9 \%$, respectively. In $A$. indica, except for $\mathrm{Ag}$, the atomic percentages of carbon $(\mathrm{C})$, chlorine $(\mathrm{Cl})$, oxygen $(\mathrm{O})$, and aluminum $(\mathrm{Al})$ were $38.5 \%, 38.5 \%, 1.7 \%$, and $1.2 \%$, respectively. The peak of carbon in the spectrum represents the adsorbed constituents of the leaf extracts, and the other peaks of oxygen and chlorine are formed because of plant element adsorption over Ag NPs. Carbon is a fundamental chemical constituent in both the $C$. roseus and $A$. indica leaf chemical structures. In C. roseus and A. indica, carbon sources are abundant in leaf extracts. The synthesized Ag NPs were washed several times with double-distilled water after synthesis to minimize contamination. Because ofthe agglomeration of phytochemicals present on the Ag NPs, there was a high amount of carbon on the green-synthesized Ag NPs. The presence of a high content of aluminum (Al) was probably due to the inclusion of the microscope stage in the analysis. Apart from carbon, the remaining elements showed a drastically decreased atomic percentage compared with silver; the EDX spectrum gives evidence of formed particles through bioreduction of plant leaf extracts, with $\mathrm{AgNO}_{3}$ confirmed as $\mathrm{Ag} \mathrm{NPs}$. 


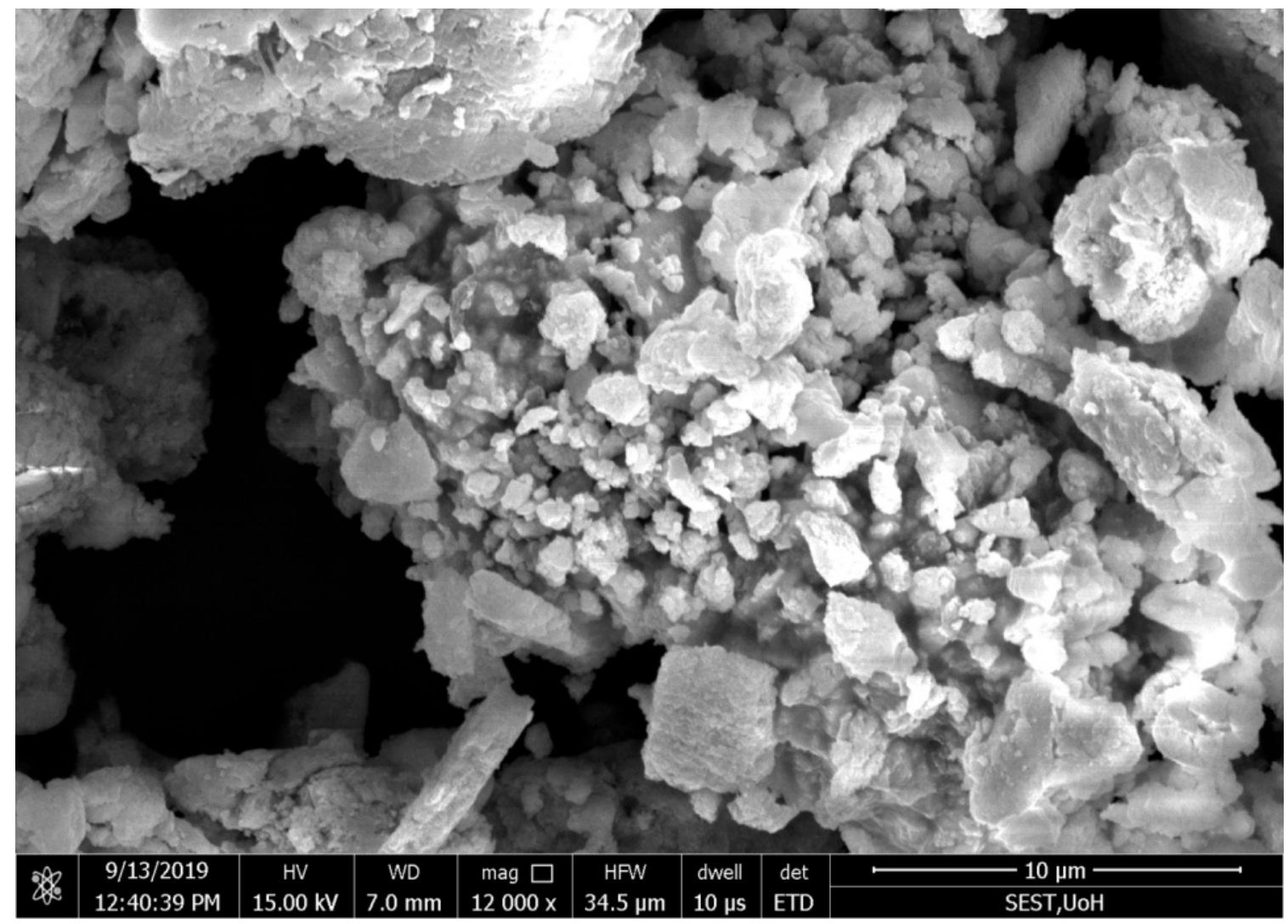

(a)

Yogi vemana university | sample | Area 125 | Full Area 1

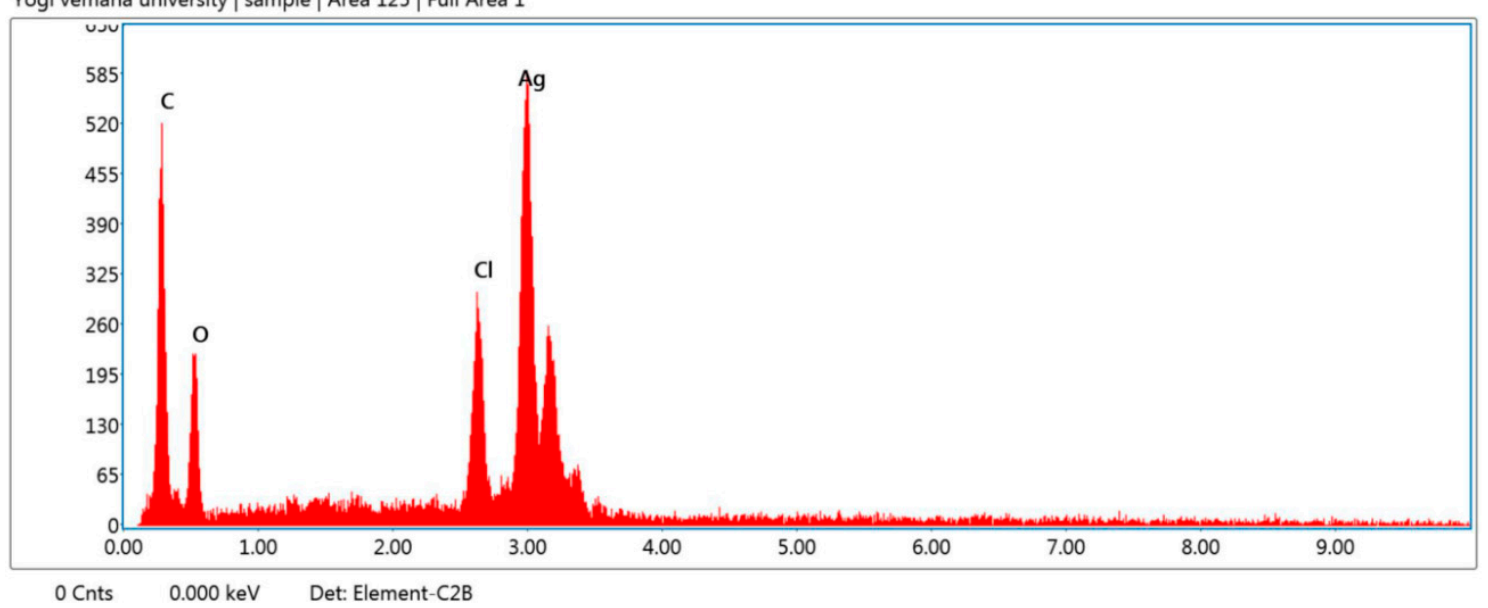

(b)

Figure 4. (a) Scanning electron microscopy(SEM) images of synthesized Ag NPs from Catharanthus roseus; (b) energy dispersive X-ray (EDX) spectrum of C Ag NPs showing the presence of different phytoelements as capping agents. 


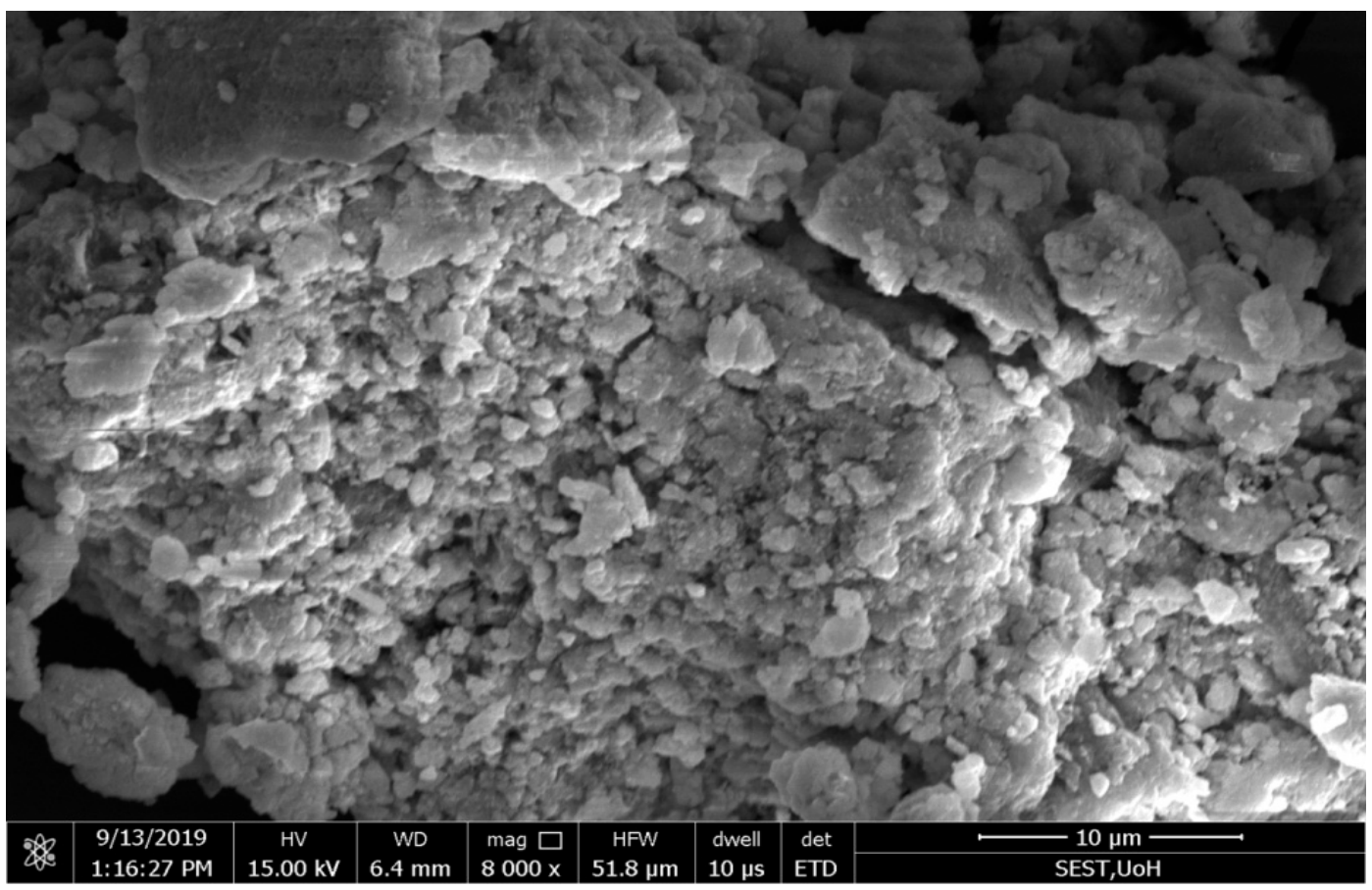

(a)

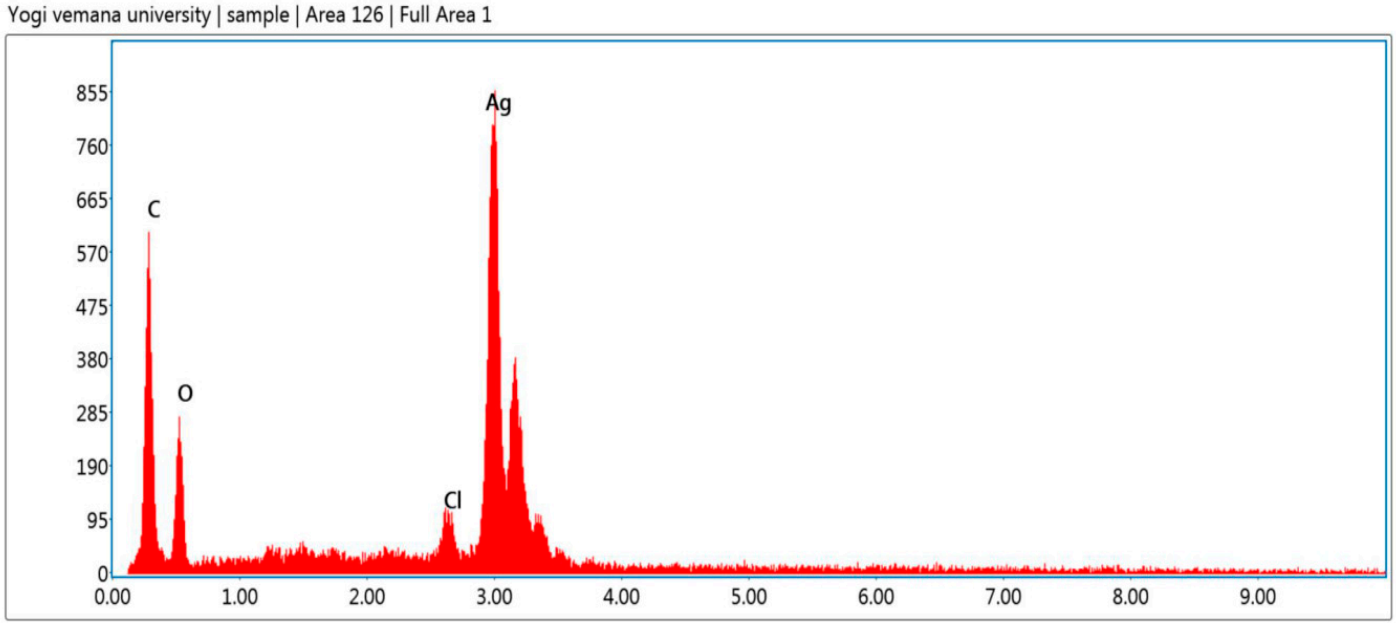

(b)

Figure 5. (a) Scanning electron microscopy (SEM) images of synthesized Ag NPs from Azadirachta indica; (b) energy dispersive X-ray (EDX) spectrum of A Ag NPs showing the presence of different phytoelements as capping agents.

\subsection{Transmission Electron Microscopy}

The morphology (size and shape) of C Ag NPs and A Ag NPs were analyzed using TEM (JEOL, Japan) at an operating voltage of $200 \mathrm{kV}$. The synthesized C Ag NPs and A Ag NPs were transferred into a new vial. The sample was prepared by mixing with $95 \%$ alcohol and then $15 \mathrm{~min}$ of ultra-sonication in an ultrasonic water bath. A nanoparticlesaqueous solution $(5 \mu \mathrm{L})$ was placed on coated carbon grids and air-dried immediately before screening. TEM grids were prepared by placing a drop of particle solution on a carbon-coated $\mathrm{Cu}$ grid and drying under a lamp. The characteristics of the $\mathrm{Ag}$ NPs synthesized using $C$. roseus and $A$. indica leaf aqueous extracts were examined using TEM. Ag NPs 
acquired through the green route with $10 \%(w / v)$ of $C$. roseus and $A$. indica leaf extracts in $1 \mathrm{mM} \mathrm{AgNO}_{3}$ showed particle sizes ranging 10-200 nm (average diameter $30 \mathrm{~nm}$ ), as shown in Figure 6.

A
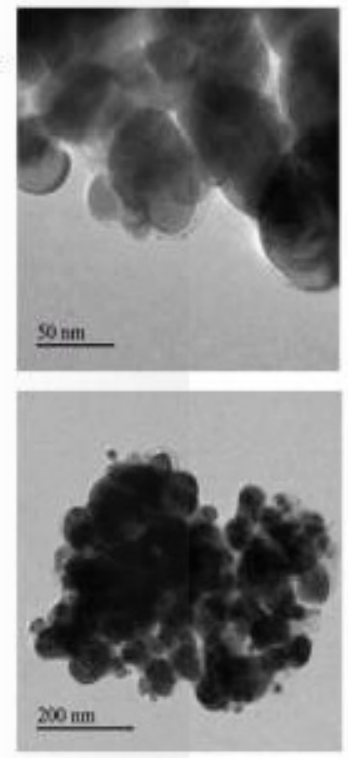
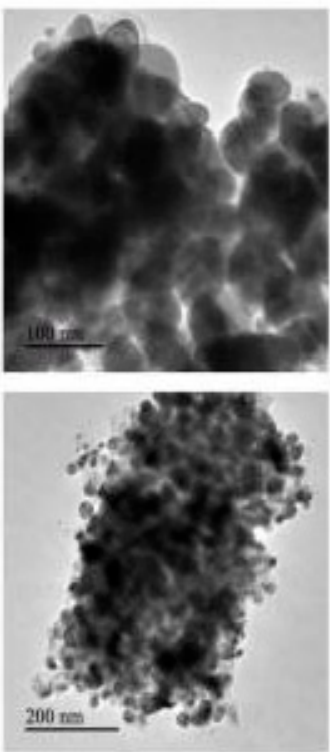

B
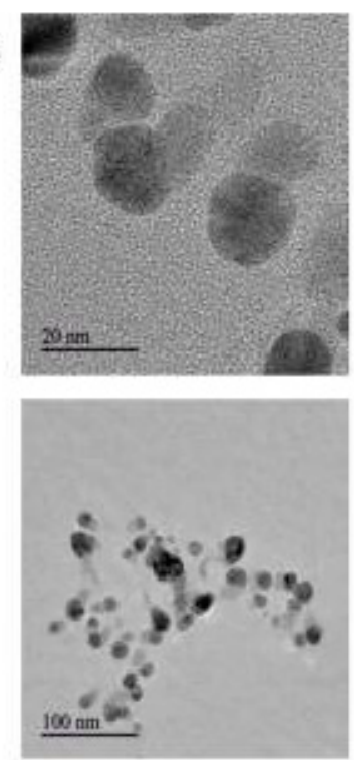
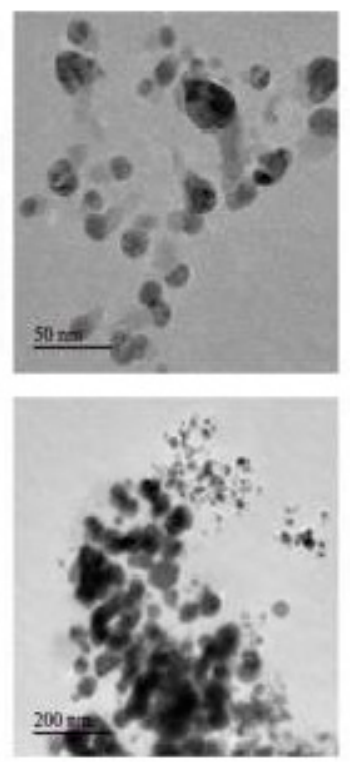

Figure 6. Transmission electron microscopy (TEM) images of biosynthesized silver nanoparticles from (A) Catharanthus roseus and (B) Azadirachta indica plant extracts.

TEM images of the green-synthesized Ag NPs revealed that silver nanoparticles were predominantly spherical in shape; a few agglomerated Ag NPs were also observed, which indicates possible sedimentation at a later time. C. roseus TEM images revealed that there was variation in particle sizes, with a range from 20 to $50 \mathrm{~nm}$, and the average particle size was found to be $30 \mathrm{~nm}$ [50]. The TEM images showed that the Ag NPs were agglomerated and embedded in a dense, thick pattern, possibly acting as stabilizing chemical constituents in the leaf extracts of $C$. roseus and A. indica.

\subsection{Antibacterial Activity of Silver Nanoparticles}

\subsubsection{Antibiotic Susceptibility Test}

The green-synthesized C Ag NPs and A Ag NPs showed effective bacteriolytic activity against MDR bacteria (E. coli, K. pneumoniae, S. aureus, and P. aeruginosa) isolated from wound infections. The green-synthesized C Ag NPs showed high antibacterial activity against both gram-negative (E. coli, K. pneumonia, P. aeruginosa) and gram-positive (S. aureus) bacteriaby showing a wider range of inhibitory zones compared to A Ag NPs at various concentrations (10, 30, 60, 90, and $120 \mu \mathrm{g} / \mu \mathrm{L})$, as shown in Figure 7 and Table 1. The maximum bacteriolytic activity of green-synthesized C Ag NPs and A Ag NPs was shown as 19and 16-mm zones of inhibition at the highest concentration against K. pneumoniae, respectively. C Ag NPs showed more bacteriolytic activity at all tested concentrations compared to A Ag NPs, as described in Table 1.The saturation dose of Ag NPs for that specific tested species was optimized at lower concentrations, so the inhibition zone did not increase even when the doses of Ag NPs were increased. The exact mechanism of green-synthesized Ag NPs dose-exclusion in MDR bacteria is still unknown. 


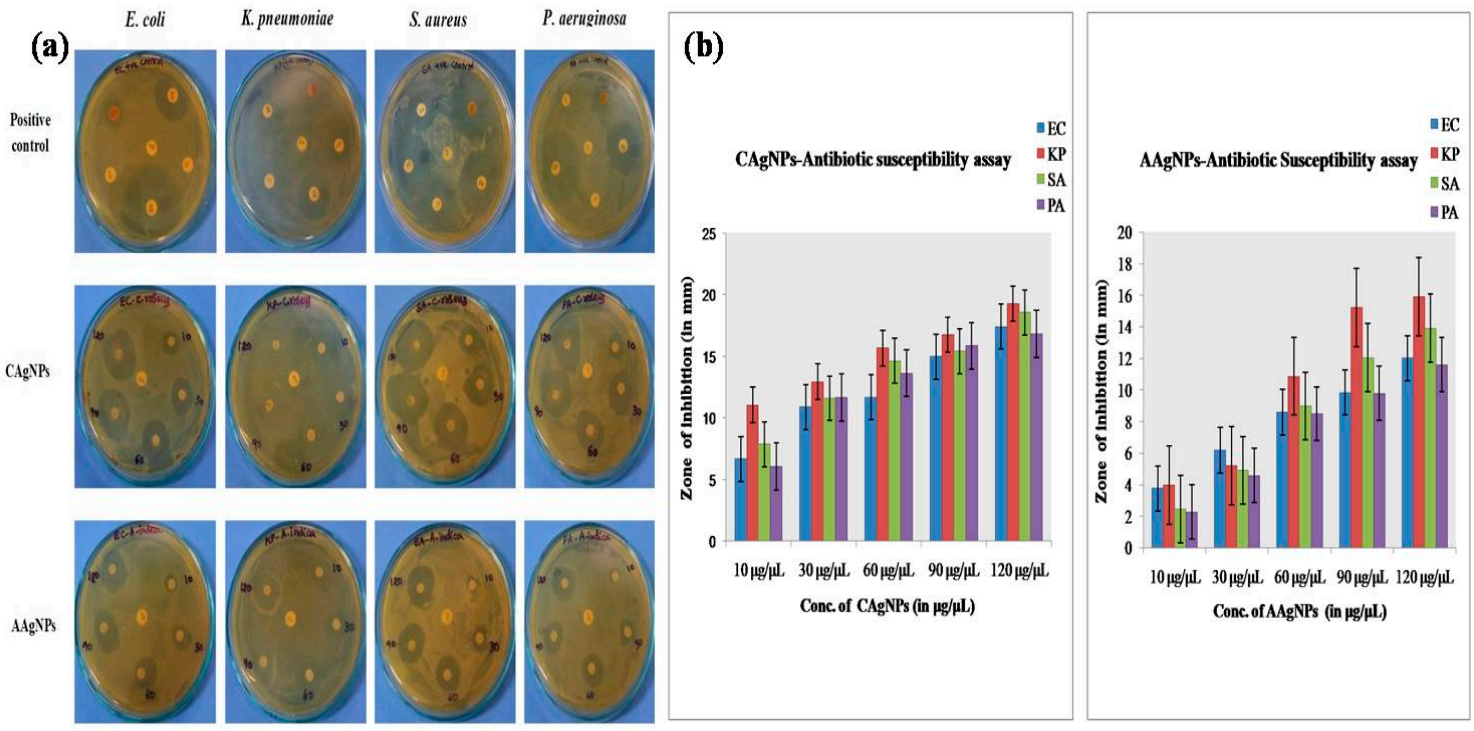

Figure 7. (a)Antibiotic susceptibility activity of biosynthesized silver nanoparticles (C Ag NPs and A Ag NPs) demonstrated by the disc diffusion method in multidrug-resistant (MDR) bacteria. (b) Graphical representation of antibiotic susceptibility activity of green-synthesized Ag NPs. EC-Escherichia coli, $\mathrm{KP}$-Klebsiella pneumoniae, SA—Staphylococcus aureus, and PA-Pseudomonas aeruginosa.

Table 1. Antibiotic susceptibility test of MDR bacteria and the zone of inhibition for different concentrations of green-synthesized silver nanoparticles.

\begin{tabular}{ccccccccc}
\hline \multirow{2}{*}{$\begin{array}{c}\text { Ag NPs } \\
\text { Conc. }\end{array}$} & \multicolumn{3}{c}{$\begin{array}{c}\text { C. roseus Silver Nanoparticles } \\
\text { (Mean Zone of Inhibition in } \mathbf{~ m m ) ~}\end{array}$} & \multicolumn{4}{c}{$\begin{array}{c}\text { A. indica Silver Nanoparticles } \\
\text { (Mean Zone of Inhibition in mm) }\end{array}$} \\
\cline { 2 - 9 } & EC & KP & SA & PA & EC & KP & SA & PA \\
\hline $10 \mu \mathrm{g} / \mu \mathrm{L}$ & 7 & 11 & 8 & 6 & 4 & 4 & 2 & 2 \\
\hline $30 \mu \mathrm{g} / \mu \mathrm{L}$ & 11 & 13 & 12 & 12 & 6 & 5 & 5 & 5 \\
\hline $60 \mu \mathrm{g} / \mu \mathrm{L}$ & 12 & 16 & 15 & 14 & 9 & 11 & 9 & 8 \\
\hline $90 \mu \mathrm{g} / \mu \mathrm{L}$ & 15 & 17 & 15 & 16 & 10 & 15 & 12 & 10 \\
\hline $120 \mu \mathrm{g} / \mu \mathrm{L}$ & 17 & 19 & 19 & 17 & 12 & 16 & 14 & 12 \\
\hline EC-Escherichia coli, & KP-Klebsiella pneumoniae, SA-Staphylococcus aureus, and PA—Pseudomonas aeruginosa.
\end{tabular}

\subsubsection{Bacterial Reduction Assay}

The bacterial growth inhibitory activity of C Ag NPs and A Ag NPs against MDR bacteria (E. coli, K. pneumoniae, S. aureus, and P. aeruginosa) at various time points (1, 3, 5, and $7 \mathrm{~h}$ of incubation) and concentrations (ranging from 10 to $100 \mu \mathrm{g} / \mu \mathrm{L}$ ) were measured using a bacterial reduction assay. Interestingly, P. aeruginosa $(80 \mu \mathrm{g} / \mu \mathrm{L})$ required a higher amount of green-synthesized nanoparticles of $C$. roseus and $A$. indica to inhibit growth than the gram-positive bacteria $S$. aureus $(10 \mu \mathrm{g} / \mu \mathrm{L})$. For K. pneumoniae and E. coli, $10 \mu \mathrm{g} / \mu \mathrm{L}$ of synthesized nanoparticles was required for the inhibition of growth of MDR bacteria. The nanoparticles that were green-synthesized with different concentrations of $A$. indica and $C$. roseus were proven effective antibacterial agents against MDR bacteria. The results for C Ag NPs and A Ag NPs are represented in Figure 8A,B, respectively. The bacterial growth on MH-Agar (Mueller-Hinton agar) of E. coli and K. pneumoniae showed that lower concentrations of C Ag NPs (40-50 $\mu \mathrm{g} / \mu \mathrm{L})$ are optimum for inhibition. There is no significant inhibitory action obtained by increasing the concentration of C Ag NPs on MH-Agar for E. coli and K. pneumoniae. Therefore, $50 \mu \mathrm{L}$ is the optimum/saturated concentration required for inhibitory action on S. aureus and P. Aeruginosa by C Ag NPs. No significant inhibitory action on bacterial growth was observedby increasing the dose 
volume of C Ag NPs. The tested species, especially S. aureus and P. aeruginosa, probably follow the dose-exclusion mechanism.However, at the highest concentration $(100 \mu \mathrm{L})$, we found bacteriolytic activity in almost all strains. The exact mechanism of the inhibitory action of green-synthesized Ag NPs on bacterial growth is not known. The green-synthesized C Ag NPs and A Ag NPs showed significant bacteriolytic activity compared with several other plant extracts alone or silver nitrate alone. Yliniemi et al. demonstrated that the biosynthesized Ag NPs effectively cause cell death of MDR bacteria through various mechanisms of action on bacterial respiration and cell membrane permeability [51]. Rai et al. and other groups revealed that the smaller size of biosynthesized Ag NPs provides a large surface area, which ensures a more significant outcome compared with commercial silver (Ag) on bacteria [52-54]. Gurunathan et al. demonstrated the dose-dependent bactericidal activity of Ag NPs at concentrations ranging from 0.1 to $1.0 \mu \mathrm{g} \mathrm{mL}-1$ against two gram-negative and two gram-positive bacterial strains. They showed that the antibacterial activity of Ag NPs at low concentrations was more effective against gram-negative bacteria than gram-positive bacteria. They found that cell viability was reduced, and no growth at MIC values was observed for both strains. Thus, the bactericidal effect depends on the concentration, and it is specific for each bacterial strain. Positively charged Ag NPs show bactericidal and bacteriostatic activity, as reviewed by Roy et al. (2019). They found that the antibacterial activity of Ag NPs at a $100 \mu \mathrm{g} \mathrm{mL} \mathrm{m}^{-1}$ concentration was slightly higher than that at $450 \mu \mathrm{g} \mathrm{mL}^{-1}$ compared to the control $[55,56]$. Our data demonstrated that although there was no dependence on concentration, at a higher concentration $(100 \mu \mathrm{L})$, we observed bactericidal activity using a bacterial reduction assay.
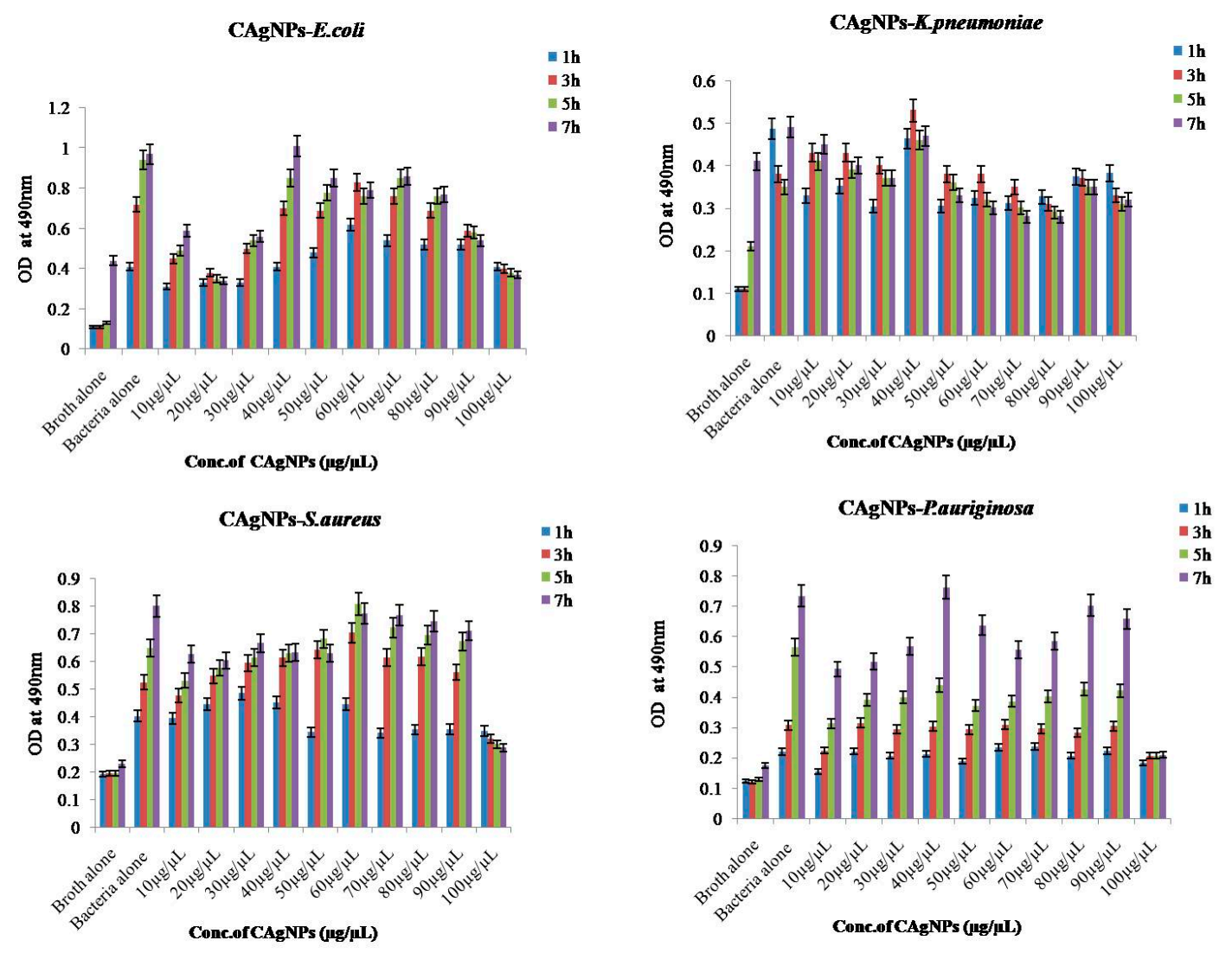

(A)

Figure 8. Cont. 

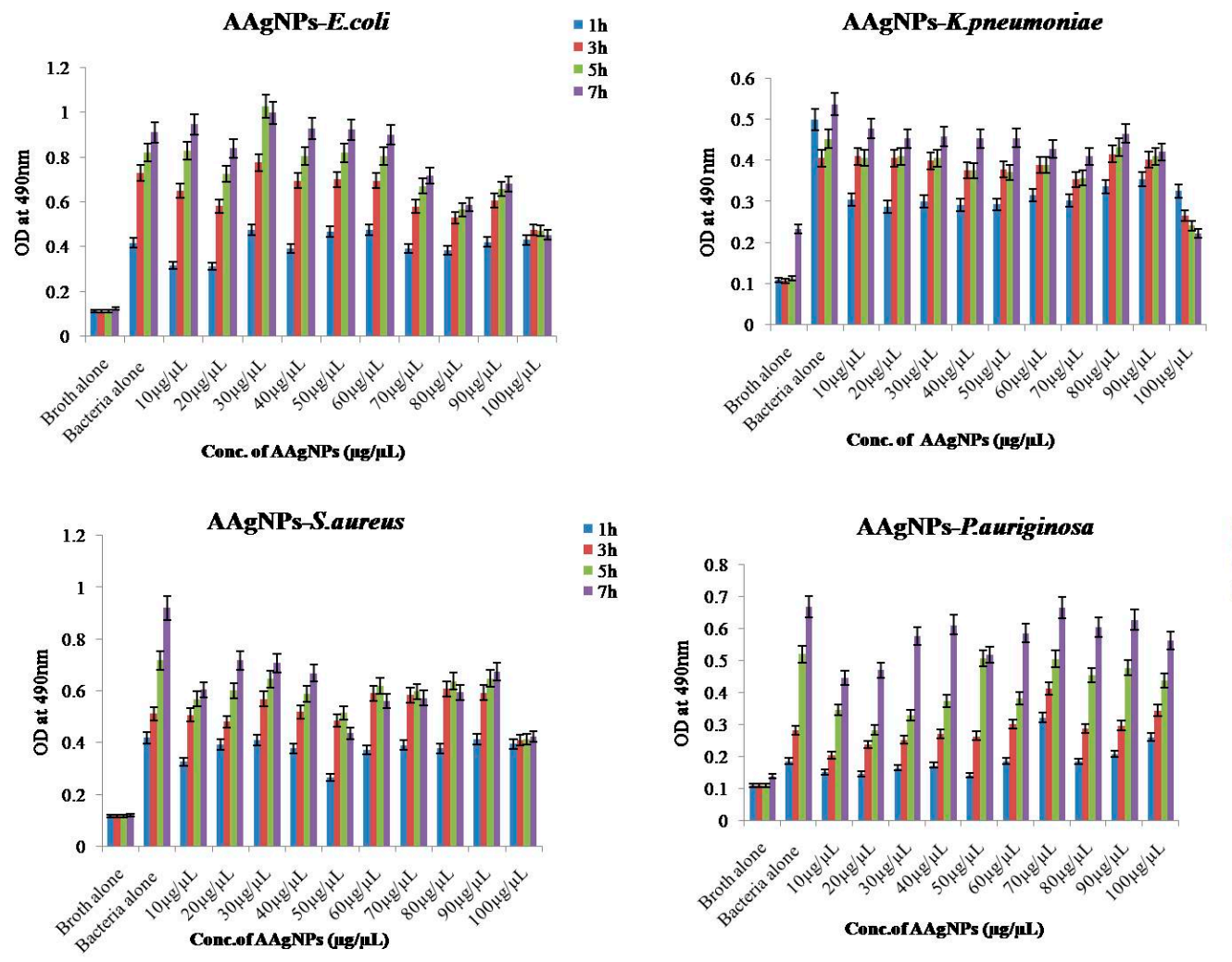

(B)

Figure 8. (A) Turbidity test for C. roseus Ag NPs (C Ag NPs) in MDR bacteria. (B) Turbidity test for A. indica Ag NPs (A Ag NPs) in MDR bacteria.

According to Sahayaraj et al., biosynthesized Ag NPs further attached to the cell surface of bacteria and entered the bacteria, leading to DNA replication, interruption of adenosine triphosphate (ATP) production, and ROS generation, directly affecting the cell framework [57]. Moreover, the silver bactericidal effect was possibly related to the inactivation of phosphomannose isomerase catalysis and is involved in the transition of mannose-6-phosphate to fructose -6-phosphate, a key arbitrate in glycolysis and a common sugar catabolism mechanism in microorganisms [58].

\subsection{Wound-Healing Efficacy of Silver Nanoparticles In Vivo}

The wound-healing efficacy of C Ag NPs and A Ag NPs was evaluated using female BALB/c mice using an excision wound-healing model with $5 \mathrm{~mm}$ biopsy punches. The wounds were generated on the skin surface dorsally, nano-formulations were applied on alternate days (on days 1, 3, 5, 7, 9, 11), and pictures were taken. Povidone-iodine ointment that is available on the market was used as a positive control for treated mice. As depicted in Figure 9A, green-synthesized silver nanoparticles (C Ag NPs and A Ag NPs)-treated mice showed enhanced wound constriction efficacy when compared to control and positive-control groups. The wound beds where the green-synthesized Ag NPs were topically applied showed no microbial growth, hemorrhage, or formation of pus throughout treatment, while the control group wounds showed remarkable irritation. The green-synthesized silver-nanoparticles-treated animals showed better wound-healing capacity from day 1 onwards and decreased wound size throughout the remaining days of treatment when compared to control group animals. At the end of the study, the wounds exhibited approximately $94 \% \pm 1 \%(p<0.01)$ constriction after treatment with C Ag NPs and $87 \% \pm 1 \%(p<0.01)$ closure in the A Ag NPs group, whereas the control wound exhibited approximately $74 \% \pm 1 \%$ closure and the positive control (povidone-iodine) and vehicle control (Vaseline) wounds showed $79 \% \pm 1 \%$ and $76 \% \pm 1 \%$ wound 
constriction, respectively (Figure 9B and Table 2).The decreased size of wounds and increased healing efficacy could possibly be explained by the green-synthesized Ag NPs microbial efficacy towards microbial infection surrounding the region of the wound. Mondal et al. demonstrated that tissue regeneration of damaged sites is well-recognized in wound healing experiments, and the outcomes were satisfactory in earlier studies of wound constriction [59].The C Ag NPs-treated group showed an improvement in whole wound appearance following decreased irritation, as shown by alleviated inflammation and negligible bruising on day 11 of the experiment. The experimental results revealed that the healing capacity of wounds treated with $C$. roseus silver nanoparticles was greater than that of A. indica silver nanoparticles.

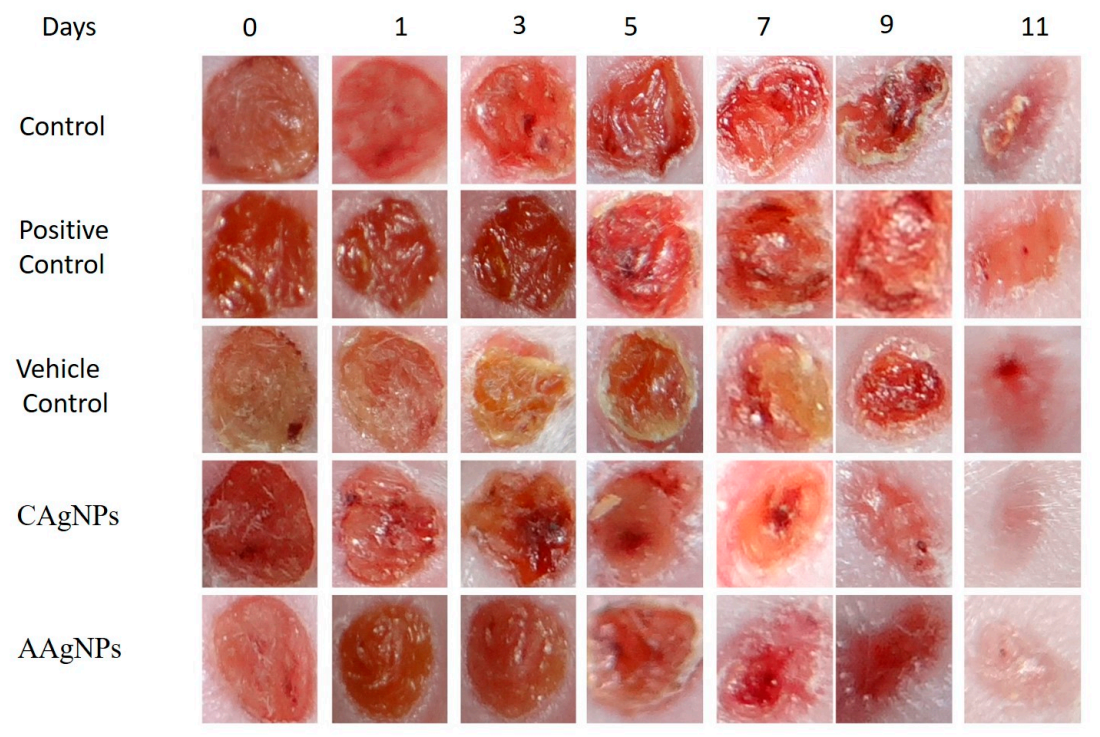

(A)

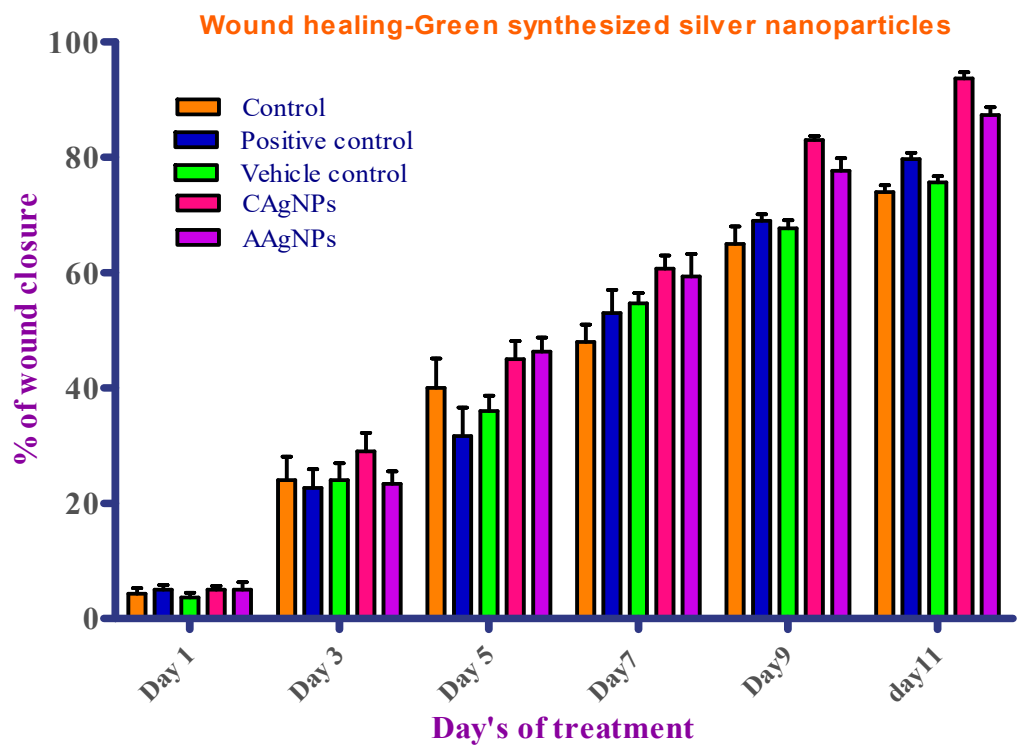

(B)

Figure 9. (A) Representative photographs showing wound closure after treatment with greensynthesized silver nanoparticles of C. roseus and A. indica $(1 \% w / w)$ and control groups on days $0,1,3,5$, 7, 9, and 11. (B) Effect of topical application of green-synthesized silver nanoparticles of C. roseus and A. indica $(1 \% w / w)$ on percent wound closure on different days in BALB/c mice. 
Table 2. Percentage of wound contraction in BALB/c mice excision wound model. Note: mean \pm SE.

\begin{tabular}{cccccccc}
\hline \multirow{2}{*}{ Group } & \multirow{2}{*}{ Treatment Groups } & \multicolumn{6}{c}{ \% of Wound Contraction in Days } \\
\cline { 3 - 8 } & & $\mathbf{1}$ & $\mathbf{3}$ & $\mathbf{5}$ & $\mathbf{7}$ & $\mathbf{9}$ & $\mathbf{1 1}$ \\
\hline Group-I & Control & $4 \pm 1$ & $24 \pm 4$ & $40 \pm 5$ & $48 \pm 3$ & $65 \pm 3$ & $74 \pm 1$ \\
\hline Group-II & $\begin{array}{c}\text { Betadine } \\
\text { (Povidone-Iodine) }\end{array}$ & $5 \pm 1$ & $23 \pm 3$ & $32 \pm 5$ & $53 \pm 4$ & $69 \pm 1$ & $79 \pm 1$ \\
\hline Group-III & Vaseline & $4 \pm 1$ & $24 \pm 3$ & $36 \pm 3$ & $55 \pm 2$ & $68 \pm 1$ & $76 \pm 1$ \\
\hline Group-IV & $1 \%$ C. roseus Ag NPs & $5 \pm 1$ & $29 \pm 3$ & $45 \pm 3$ & $60 \pm 2$ & $83 \pm 1$ & $94 \pm 1$ \\
\hline Group-V & $1 \%$ A. indica Ag NPs & $5 \pm 1$ & $23 \pm 2$ & $46 \pm 2$ & $59 \pm 4$ & $78 \pm 2$ & $87 \pm 1$ \\
\hline
\end{tabular}

According to Tian et al., the significant action of green-synthesized Ag NPs in the healing of wounds in mice is attributed to faster regeneration, which is preferred for improved appearanceand occurs in a dose-dependent manner. In addition, green-synthesized Ag NPs showed positive results throughout the experiment due to their antibacterial efficacy and ability to decrease inflammation of wounds by diminishing the infiltration of mast cells and lymphocytes and the modification of cytokines with a fibrogenic nature [60]. Correspondingly, Liu et al. showed the efficacy of green-synthesized Ag NPs in epidermal re-epithelialization and dermal contraction, demonstrating that green-synthesized Ag NPs might enhance the percentage of wound constriction. Their characteristic wound-healing nature was explained by enhanced keratinocytes production and their movement in damaged wound sites [61]. Additionally, green-synthesized Ag NPs may possibly improve the differentiation of fibroblasts to myofibroblasts, thus increasing the healing capacity of wounds [62].

In the current study, the biosynthesized Ag NPs demonstrated significant potency in wound healing by enhancing the proliferation and migration of fibroblasts. The Ag NPs synthesized from C. roseus and $A$. indica enhanced the differentiation of fibroblasts into myofibroblasts and eventually improved wound contraction [63]. Nowadays, Ag NPs coated with biomedical products are commonly used to avoid microbial ailments by enhancing the healing capacity of wounds [64]. Current in vitro and in vivo studies have proven that the synthesized Ag NPs show effective antimicrobial activity against MDR bacteria that causes infections on the skin.

\section{Materials and Methods}

\subsection{Leaf Extracts Preparation from C. roseus and A. indica}

Leaf extracts from C. roseus and A. indica plants were prepared and used to synthesize silver nanoparticles. Young leaves of $C$. roseus and A. indica were obtained from Yogi Vemana University $\left(14.473786^{\circ} \mathrm{N}, 78.711482^{\circ} \mathrm{E}\right.$; premises in Kadapa, Andhra Pradesh, India). Leaves were cleaned thoroughly to remove the debris and other organic constituents and dried at $37^{\circ} \mathrm{C}$. Powder was made from dried leaves, and $10 \mathrm{~g}$ of this powder was mixed with $100 \mathrm{~mL}$ distilled water $(10 \% \mathrm{w} / \mathrm{v})$ in a conical flask and then boiled for $1 \mathrm{~h}$ at $80^{\circ} \mathrm{C}$. The brown leaf extract was filtered through Whatmann No. 1 paper and preserved at $4{ }^{\circ} \mathrm{C}$.

\subsection{Preparation of Silver Nanoparticlesfrom Leaf Extract}

Green synthesis of silver nanoparticles (AgNPs) was performed following the method of Sulaiman et al. [65]. Phytoextracts $(1 \mathrm{~mL})$ were mixed with different concentrations of silver nitrate $\left(\mathrm{AgNO}_{3}\right)\left(\mathrm{GR}\right.$ Merck, India), ranging from $1-5 \mathrm{mM}$. This step was carried out at $37^{\circ} \mathrm{C}$ in the dark to reduce $\mathrm{AgNO}_{3}$. The reduction of silver ions to silver nanoparticles was determined by the change in color to dark brown. The prepared Ag NPs were also validated using spectroscopy. 


\subsection{Microbial Strains}

Prevalent MDR bacterial strains were generously gifted to us by the Microbiology Department of Yogi Vemana University. The potent drug-resistant bacterial strains of E. coli, K. pneumoniae, S. aureus, and $P$. aeruginosa were utilized to evaluate the antibacterial and wound healing properties of silver nanoparticles of $C$. roseus and $A$. indica.

\subsection{Silver Nanoparticles Characterization}

Ag NPs were characterized by X-ray diffraction (XRD) using Rigaku Miniflex with $\mathrm{Cu} \mathrm{K} \alpha$ radians at $2 \theta$ angles varying from $20^{\circ}$ to $80^{\circ}$. Optical properties were investigated using DRS UV Visible spectra, with a frequency varying from 500 to $4000 \mathrm{~cm}^{-1}$ and $4 \mathrm{~cm}^{-1}$ resolution.FTIR spectra were recorded by employing KBr disks using an FTIR spectrometer (Perkin Elmer, Spectrum 2) with a wave number of 4000-400 $\mathrm{cm}^{-1}$ [66]. Dynamic light scattering was performed using a Zetasizer-Nano ZS based on a conventional approach with several variations. Silver nanoparticles $(100 \mu \mathrm{g} / \mathrm{mol})$ were sonicated for $2 \mathrm{~min}$, and dynamic particle sizes were assessed by adding two drops of nanoparticles into $10 \mathrm{~mL}$ of Millipore water. Once the nanoparticles were widely dispersed in water, the nanoparticles size was measured with a DLS analyzer. The analyses were repeated many times to attain a standard size of nanoparticles. Ag NPs (1 mg/mL) were prepared in Milli-Q water and used for further analysis. The morphology, particle size, and microstructure of Ag NPs were examined by high-resolution scanning electron microscopy [46] (Nikon, Japan). Briefly, $1 \mathrm{mg} / \mathrm{mL}$ of Ag NPs was sonicated to obtain a homogenous suspension. A sonicated stock solution was used for the size measurement of silver, which was diluted many times. Images were captured using one drop of dried gold-coated sample. Particle size, shape morphology, and fine pattern were evaluated with higher resolution TEM in a JEOL3010 (Japan) operated at $200 \mathrm{kV}$, following the protocol reported by Chattopadhyay et al. [67]. The solution was developed by adding 95\% alcohol and performing 15 min of ultra-sonication. One drop of Ag NPs was placed on a carbon-coated grid and allowed to dehydrate prior to examination. TEM grids were made by adding a drop of Ag NPs onto carbon-coated $\mathrm{Cu}$ grids and allowing them to dry. Images were then taken.

\subsection{Antibacterial Activity of Silver Nanoparticles}

The antibacterial activities of Ag NPs were evaluated using previously isolated MDR bacterial isolates such as E. coli, K. pneumoniae, S. aureus, and P. aeruginosa from wound infection patients [12]. Different concentrations, ranging from 10 to $120 \mu \mathrm{g} / \mu \mathrm{L}$ of Ag NPs obtained from C. roseus and A. indica, were tested for antibacterial activity against MDR bacteria using the agar well diffusion method and the micro titer plate method. The positive controls used were tetracycline (30 $\mu \mathrm{g})$, ampicillin (30 $\mu \mathrm{g})$, and erythromycin $(20 \mu \mathrm{g})$, and the negative control was deionized water. Antibacterial activity was measured by the zone of inhibition, and the experiment was performed in triplicate.

\subsection{Wound Healing Activity of Silver Nanoparticles}

Female BALB/c mice were procured from Mahaveera Enterprises (Reg.no:1656/PO/Bt/S/12/ CPCSEA, Hyderabad, India). BALB/c mice (20-25 g) aged 8-10 weeks were housed at the YVU animal house following the laboratory animal procedures approved by the Institute Animal Ethics Committee (IAEC; CPCSEA no: 1841/GO/Re/S/51/CPCSEA). All procedures were conducted in accordance with the Guide for the Care and Use of Laboratory Animals. The anesthesia dose was $5 \mathrm{~mL}$, with $2 \mathrm{~mL}$ ketamine $(50 \mathrm{mg} / \mathrm{mL}), 0.5 \mathrm{~mL}$ xylazine $(2 \%)$, and $2.5 \mathrm{~mL}$ saline $(9 \%)$. The hair on the dorsal skin of the animalwas removed with an artificial hair removal cream [68] and wiped with $70 \%$ ethanol. Mice were anesthetized with $40-50 \mu \mathrm{L}$ of a ketamine and xylazine mixture, depending on the weight of the animal, and a full-thickness open excision wound was made with a 5-mm biopsy punch. Following recovery from anesthesia, micewere housed separately in appropriately sanitized cages. The laboratory mice were distributed evenly and randomly separated into five 
groups as follows: Group I as the PBS- negative control, Group II as the betadine-positive control (povidone-iodine ointment-treated), Group III as the vehicle control (Vaseline-treated), GroupIV as 1\% $w / w$ nano-formulation- 1 (C. roseus Ag NPs-treated), and Group V as the $1 \% w / w$ nano-formulation-2 (A. indica Ag NPs-treated). We pre-formulated $1 \mathrm{mg}$ of green-synthesized silver nanoparticles (C Ag NPs and A Ag NPs), ground in $1 \mathrm{~g}$ of Vaseline (1 mg Ag NPs per $1 \mathrm{~g}$ Vaseline), and prepared a fine paste using a motor and pestle $(\sim 50 \mu \mathrm{L})$ for topical application towound surfaceson alternative days for 14 days. Wound constriction was observed by monitoring the wounds at days $0,1,3,5,7,9$, and 11, and wound closure (in $\mathrm{mm}$ ) was measured alternatively using a digital Vernier caliper. Wound recovery efficacy is represented as the percentage of wound contraction rate (WCR).

The percentage of wound contraction rate $=$ original wound area - actual wound area/original wound area $\times 100$.

\section{Conclusions}

The current study demonstrates the biological production of Ag NPs via phytosynthesis using bioreductant, eco-friendly, and renewable C. Roseus and A. indica leaf extracts. Silver nanoparticleswere quickly and inexpensively synthesizedusing this method. Ag NPs were prepared from aqueous leaf extracts of $C$. roseus and $A$. indica and characterized by XRD, FT-IR, DLS, SEM-EDX, and TEM analyses and their antibacterial efficacy against MDR bacteria and ability to promote wound healing in BALB/C mice. Physical characterization methods revealed that the produced Ag NPs were extremely small and had a highly pure form in nature. Phytoderivatives such as leaf constituents and proteins of plants act as masking agents on nanoparticles. Green-synthesized Ag NPs exhibited in-vivo wound healing efficacy and antibacterial activity against MDR E. coli, K. pneumoniae, S. aureus, and P. aeruginosa strains. Green-synthesized Ag NPs are one alternative for the management of MDR microbial inflammation; thus, green-synthesized Ag NPs may be used for the management of wounds. Using emerging applicable nanotechnology, we synthesized metallic Ag NPs through a green route and evaluated the antibacterial and wound healing properties. Based on our current results, green-synthesized Ag NPs may have potential applications as pharmaceutical agents for antibacterial activity against MDR bacteria and wound healing.

Author Contributions: V.L., M.C.R., and R.R.P. conceived the experiment; V.L., M.C.R., and R.R.P. performed the experiments; M.C.R., K.R.R., I., A.L.B. and D.L. interpreted the results; V.L., M.C.R., K.R.R., I., C.V.R., and D.L. wrote the first version, and all authors contributed to improving the paper. All authors have read and agreed to the published version of the manuscript.

Funding: The Deanship of Scientific Research (DSR) at King Abdulaziz University, Jeddah, Saudi Arabia has funded this project under grant no. FP-77-42.

Conflicts of Interest: The authors of this manuscript declare no conflict of interest. 


\section{Appendix A}
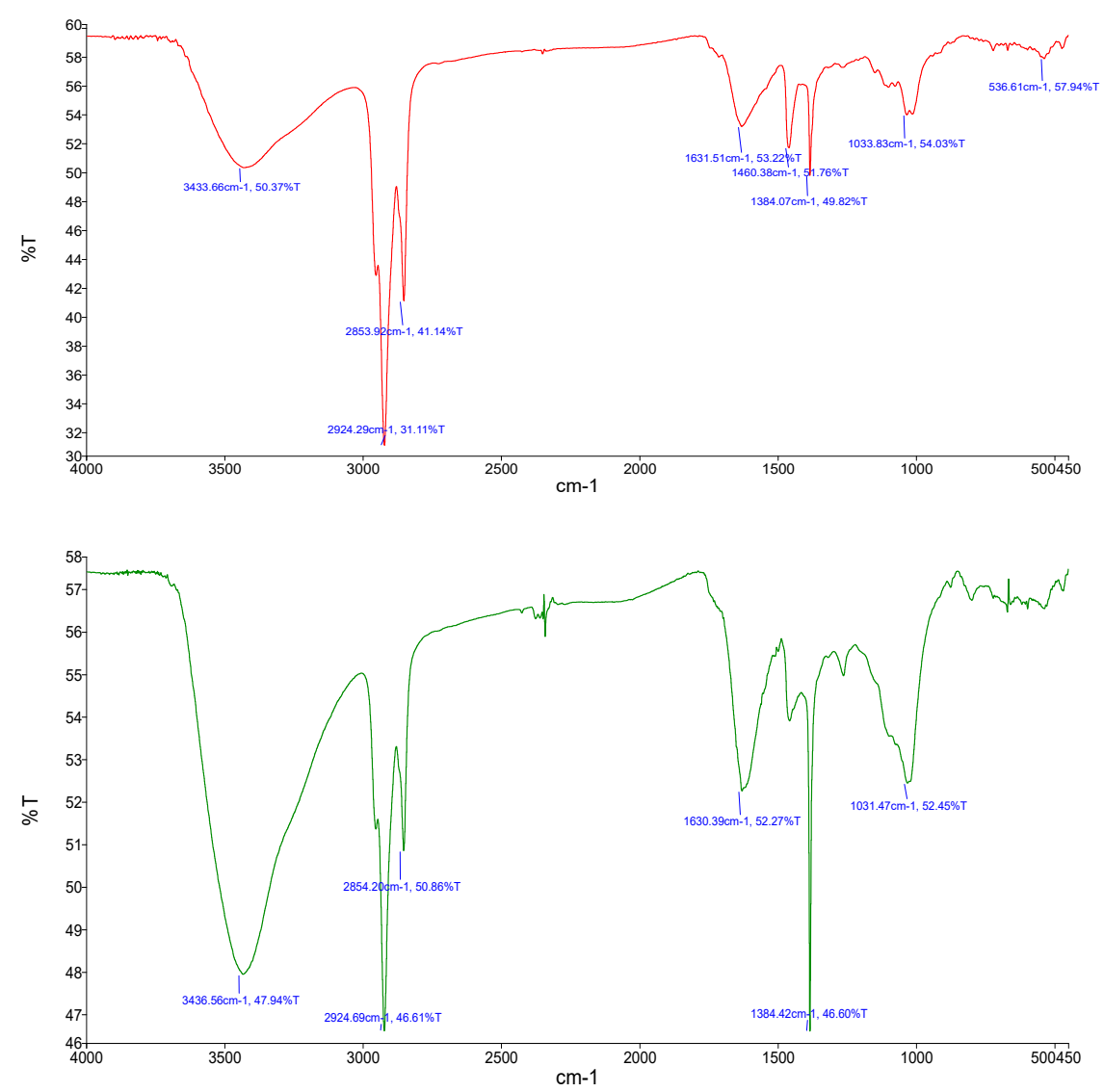

Figure A1. FTIR spectra of $C$. roseus (upper panel) and A. indica (lower panel) silver nanoparticles.
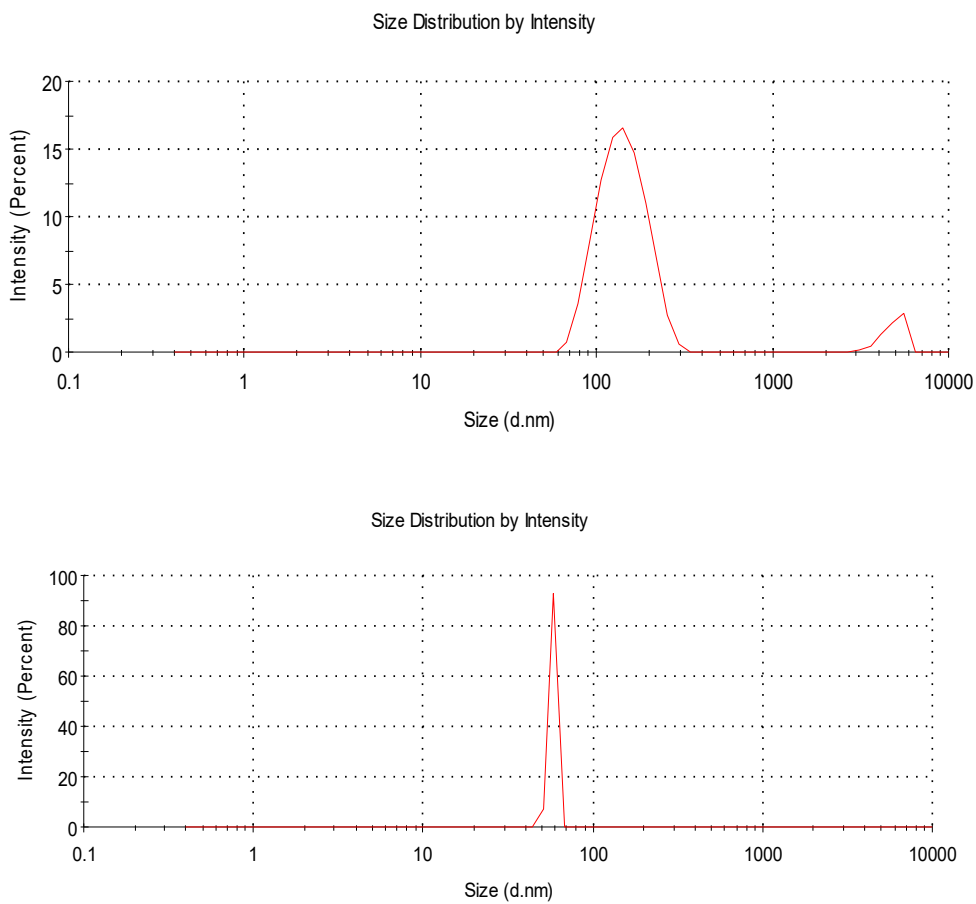

Figure A2. Hydrodynamic size determination of green-synthesized Ag NPs of C. roseus (upper panel) and A. indica (lower panel), as determined by dynamic light scattering (DLS). 


\section{References}

1. Latha, T.S.; Lomada, D.; Dharani, P.K.; Muthukonda, S.V.; Reddy, M.C. Ti-O based nanomaterials ameliorate experimental autoimmune encephalomyelitis and collagen-induced arthritis. RSC Adv. 2016, 6, 8870-8880. [CrossRef]

2. Gao, W.; Wang, J. Synthetic micro/nanomotors in drug delivery. Nanoscale 2014, 6, 10486-10494. [CrossRef] [PubMed]

3. Latha, T.S.; Reddy, M.C.; Muthukonda, S.V.; Srikanth, V.V.; Lomada, D. In vitro and in vivo evaluation of anti-cancer activity: Shape-dependent properties of TiO2 nanostructures. Mater. Sci. Eng. C 2017, 78, 969-977. [CrossRef] [PubMed]

4. Palaniselvam, T.; Valappil, M.O.; Illathvalappil, R.; Kurungot, S. Nanoporous graphene by quantum dots removal from graphene and its conversion to a potential oxygen reduction electrocatalyst via nitrogen doping. Energy Environ. Sci. 2014, 7, 1059-1067. [CrossRef]

5. Schröfel, A.; Kratošová, G.; Šafařík, I.; Šafaříková, M.; Raška, I.; Shor, L.M. Applications of biosynthesized metallic nanoparticles-A review. Acta Biomater. 2014, 10, 4023-4042. [CrossRef]

6. Singh, M.; Singh, S.; Prasad, S.; Gambhir, I. Nanotechnology in medicine and antibacterial effect of silver nanoparticles. Dig. J. Nanomater. Biostructures 2008, 3, 115-122.

7. Narayanan, K.B.; Sakthivel, N. Green synthesis of biogenic metal nanoparticles by terrestrial and aquatic phototrophic and heterotrophic eukaryotes and biocompatible agents. Adv. Colloid Interface Sci. 2011, 169, 59-79. [CrossRef]

8. Mohanpuria, P.; Rana, N.; Yadav, S. Biosynthesis of nanoparticles: Technological concepts and future applications. J. Nanopart. Res. 2008, 10, 507-517. [CrossRef]

9. Kuppusamy, P.; Yusoff, M.M.; Maniam, G.P.; Govindan, N. Biosynthesis of metallic nanoparticles using plant derivatives and their new avenues in pharmacological applications-An updated report. Saudi Pharm. J. 2016, 24, 473-484. [CrossRef]

10. Mukunthan, K.; Elumalai, E.; Patel, T.N.; Murty, V.R. Catharanthusroseus: A natural source for the synthesis of silver nanoparticles. Asian Pac. J. Trop. Biomed. 2011, 1, 270-274. [CrossRef]

11. Jha, A.K.; Prasad, K.; Kumar, V.; Prasad, K. Biosynthesis of silver nanoparticles using Eclipta leaf. Biotechnol. Prog. 2009, 25, 1476-1479. [CrossRef] [PubMed]

12. Pallavali, R.R.; Avula, S.; Degati, V.L.; Penubala, M.; Damu, A.; Durbaka, V.R.P. Data of antibacterial activity of plant leaves crude extract on bacterial isolates of wound infections. Data Brief 2019, 24, 103896. [CrossRef] [PubMed]

13. Kim, J.S.; Kuk, E.; Yu, K.N.; Kim, J.-H.; Park, S.J.; Lee, H.J.; Hwang, C.-Y. Antimicrobial effects of silver nanoparticles. Nanomedicine 2007, 3, 95-101. [CrossRef] [PubMed]

14. Raffi, M.; Hussain, F.; Bhatti, T.; Akhter, J.; Hameed, A.; Hasan, M. Antibacterial characterization of silver nanoparticles against E. coli ATCC-15224. J. Mater. Sci. Technol. 2008, 24, 192-196.

15. Sondi, I.; Salopek-Sondi, B. Silver nanoparticles as antimicrobial agent: A case study on E. coli as a model for Gram-negative bacteria. J. Colloid Interface Sci. 2004, 275, 177-182. [CrossRef]

16. Carisse, O.; Van Der Heyden, H. Relationship of airborne Botrytis cinerea conidium concentration to tomato flower and stem infections: A threshold for de-leafing operations. Plant. Dis. 2015, 99, 137-142. [CrossRef]

17. Li, S.; Shen, Y.; Xie, A.; Yu, X.; Qiu, L.; Zhang, L.; Zhang, Q. Green synthesis of silver nanoparticles using Capsicum annuum L. extract. Green Chem. 2007, 9, 852-858. [CrossRef]

18. Sanghi, R.; Verma, P. Biomimetic synthesis and characterisation of protein capped silver nanoparticles. Bioresour. Technol. 2009, 100, 501-504. [CrossRef]

19. Singh, S.N.; Vats, P.; Suri, S.; Shyam, R.; Kumria, M.; Ranganathan, S.; Sridharan, K. Effect of an antidiabetic extract of Catharanthusroseus on enzymic activities in streptozotocin induced diabetic rats. J. Ethnopharmacol. 2001, 76, 269-277. [CrossRef]

20. El-Sayed, M.; Verpoorte, R. Methyljasmonate accelerates catabolism of monoterpenoid indole alkaloids in Catharanthusroseus during leaf processing. Fitoterapia 2005, 76, 83-90. [CrossRef]

21. Sidhu, O.P.; Kumar, V.; Behl, H.M. Variability in triterpenoids (nimbin and salanin) composition of neem among different provenances of India. Ind. Crops Prod. 2004, 19, 69-75. [CrossRef]

22. Melaiye, A.; Youngs, W.J. Silver and its application as an antimicrobial agent. Expert Opin. Ther. Pat. 2005, 15, 125-130. [CrossRef] 
23. Tong, S.Y.C.; Davis, J.S.; Eichenberger, E.; Holland, T.L.; Fowler, V.G. Staphylococcus aureus Infections: Epidemiology, Pathophysiology, Clinical Manifestations, and Management. Clin. Microbiol. Rev. 2015, 28, 603-661. [CrossRef] [PubMed]

24. Ansari, S.; Jha, R.K.; Mishra, S.K.; Tiwari, B.R.; Asaad, A.M. Recent advances in Staphylococcus aureus infection: Focus on vaccine development. Infect. Drug Resist. 2019, 12, 1243-1255. [CrossRef]

25. Ki, V.; Rotstein, C. Bacterial Skin and Soft Tissue Infections in Adults: A Review of Their Epidemiology, Pathogenesis, Diagnosis, Treatment and Site of Care. Can. J. Infect. Dis. Med. Microbiol. 2008, 19, 173-184. [CrossRef]

26. Dakal, T.C.; Kumar, A.; Majumdar, R.S.; Yadav, V. Mechanistic Basis of Antimicrobial Actions of Silver Nanoparticles. Front. Microbiol. 2016, 7, 1831. [CrossRef]

27. Shaikh, R.; Zainuddin Syed, I.; Bhende, P. Green synthesis of silver nanoparticles using root extracts of Cassia toral L. and its antimicrobial activities. Asian J. Green Chem. 2019, 3, 70-81.

28. Bhowmick, S.; Koul, V. Assessment of PVA/silver nanocomposite hydrogel patch as antimicrobial dressing scaffold: Synthesis, characterization and biological evaluation. Mater. Sci. Eng. C 2016, 59, 109-119. [CrossRef]

29. Pérez-Díaz, M.; Alvarado-Gomez, E.; Magaña-Aquino, M.; Sánchez-Sánchez, R.; Velasquillo, C.; Gonzalez, C.; Martinez-Gutierrez, F. Anti-biofilm activity of chitosan gels formulated with silver nanoparticles and their cytotoxic effect on human fibroblasts. Mater. Sci. Eng. C 2016, 60, 317-323. [CrossRef]

30. Hwang, E.T.; Lee, J.H.; Chae, Y.J.; Kim, Y.S.; Kim, B.C.; Sang, B.I.; Gu, M.B. Analysis of the toxic mode of action of silver nanoparticles using stress-specific bioluminescent bacteria. Small 2008, 4, 746-750. [CrossRef]

31. Sedki, M.; Mohamed, M.B.; Fawzy, M.; Abdelrehim, D.A.; Abdel-Mottaleb, M.M. Phytosynthesis of silver-reduced graphene oxide (Ag-RGO) nanocomposite with an enhanced antibacterial effect using Potamogetonpectinatus extract. RSC Adv. 2015, 5, 17358-17365. [CrossRef]

32. Femi-Adepoju, A.G.; Dada, A.O.; Otun, K.O.; Adepoju, A.O.; Fatoba, O.P. Green synthesis of silver nanoparticles using terrestrial fern (Gleichenia Pectinata (Willd.) C. Presl.): Characterization and antimicrobial studies. Heliyon 2019, 5, e01543. [CrossRef] [PubMed]

33. Srour, J.; Berg, E.; Mahltig, B.; Smolik, T.; Wollenberg, A. Evaluation of antimicrobial textiles for atopic dermatitis. J. Eur. Acad. Dermatol. Venereol. 2019, 33, 384-390. [CrossRef] [PubMed]

34. Kanchi, S.; Inamuddin; Khan, A. Biogenic synthesis of selenium nanoparticles with edible mushroom extract: Evaluation of cytotoxicity on prostate cancer cell lines and their antioxidant, and antibacterial activity. Biointerface Res. Appl. Chem. 2020, 10, 6629-6639.

35. Mulvaney, P. Surface plasmon spectroscopy of nanosized metal particles. Langmuir 1996, 12, 788-800. [CrossRef]

36. Sundarrajan, M.; Jeelani, A.; Santhanam, V.; Durgadevi, S.; Abirami, S. Effect of Concentration, $\mathrm{pH}$ and Time on the Morphology of Silver Nanoparticles Synthesized by Green Method using Phyllanthus niruri and Solanum nigrum Leaf Extracts. Int. J. Curr. Res. Rev. 2018, 10, 25-29. [CrossRef]

37. Al-Shmgani, H.S.A.; Mohammed, W.H.; Sulaiman, G.M.; Saadoon, A.H. Biosynthesis of silver nanoparticles from Catharanthus roseus leaf extract and assessing their antioxidant, antimicrobial, and wound-healing activities. Artif. Cells Nanomed. Biotechnol. 2017, 45, 1234-1240. [CrossRef]

38. Udayasoorian, C.; Kumar, R.; Jayabalakrishnan, M. Extracellular synthesis of silver nanoparticles using leaf extract of Cassia auriculata. Dig. J. Nanomater. Biostruct. 2011, 6, 279-283.

39. Wiley, B.J.; Im, S.H.; Li, Z.-Y.; McLellan, J.; Siekkinen, A.; Xia, Y. Maneuvering the surface plasmon resonance of silver nanostructures through shape-controlled synthesis. J. Phys. Chem. B 2006, 110, 15666-15675. [CrossRef]

40. Bhakya, S.; Muthukrishnan, S.; Sukumaran, M.; Muthukumar, M. Biogenic synthesis of silver nanoparticles and their antioxidant and antibacterial activity. Appl. Nanosci. 2016, 5, 755-766. [CrossRef]

41. Muthukrishnan, S.; Bhakya, S.; Kumar, T.S.; Rao, M. Biosynthesis, characterization and antibacterial effect of plant-mediated silver nanoparticles using Ceropegia thwaitesii-An endemic species. Ind. Crops Prod. 2015, 63, 119-124. [CrossRef]

42. Vanaja, M.; Annadurai, G. Coleus aromaticus leaf extract mediated synthesis of silver nanoparticles and its bactericidal activity. Appl. Nanosci. 2013, 3, 217-223. [CrossRef] 
43. Shankar, S.S.; Ahmad, A.; Pasricha, R.; Sastry, M. Bioreduction of chloroaurate ions by geranium leaves and its endophytic fungus yields gold nanoparticles of different shapes. J. Mater. Chem. 2003, 13, 1822-1826. [CrossRef]

44. Shameli, K.; Ahmad, M.B.; Zargar, M.; Yunus, W.M.Z.W.; Ibrahim, N.A.; Shabanzadeh, P.; Moghaddam, M.G. Synthesis and characterization of silver/montmorillonite/chitosan bionanocomposites by chemical reduction method and their antibacterial activity. Int. J. Nanomed. 2011, 6, 271-284. [CrossRef]

45. Mishra, A.; Kumari, M.; Pandey, S.; Chaudhry, V.; Gupta, K.; Nautiyal, C. Biocatalytic and antimicrobial activities of gold nanoparticles synthesized by Trichoderma sp. Bioresour. Technol. 2014, 166, 235-242. [CrossRef]

46. Banerjee, P.; Satapathy, M.; Mukhopahayay, A.; Das, P. Leaf extract mediated green synthesis of silver nanoparticles from widely available Indian plants: Synthesis, characterization, antimicrobial property and toxicity analysis. Bioresour. Bioprocess. 2014, 1, 3. [CrossRef]

47. Prathna, T.; Chandrasekaran, N.; Mukherjee, A. Studies on aggregation behaviour of silver nanoparticles in aqueous matrices: Effect of surface functionalization and matrix composition. Colloids Surf. A Physicochem. Eng. Asp. 2011, 390, 216-224. [CrossRef]

48. Pourmortazavi, S.M.; Taghdiri, M.; Makari, V.; Rahimi-Nasrabadi, M. Procedure optimization for green synthesis of silver nanoparticles by aqueous extract of Eucalyptus oleosa. Spectrochim. Acta Part A Mol. Biomol. Spectrosc. 2015, 136, 1249-1254. [CrossRef]

49. Amanzadeh, E.; Esmaeili, A.; Abadi, R.E.N.; Kazemipour, N.; Pahlevanneshan, Z.; Beheshti, S. Quercetin conjugated with superparamagnetic iron oxide nanoparticles improves learning and memory better than free quercetin via interacting with proteins involved in LTP. Sci. Rep. 2019, 9, 1-19. [CrossRef]

50. Gopinath, K.; Gowri, S.; Arumugam, A. Phytosynthesis of silver nanoparticles using Pterocarpus santalinus leaf extract and their antibacterial properties. J. Nanostructure Chem. 2013, 3, 68. [CrossRef]

51. Yliniemi, K.; Vahvaselka, M. Antimicrobial activity of colloidal silver nanoparticles prepared by sol-gel method. Chem 2008, 18, 199.

52. Rai, M.; Yadav, A.; Gade, A. Silver nanoparticles as a new generation of antimicrobials. Biotechnol. Adv. 2009, 27, 76-83. [CrossRef] [PubMed]

53. Dosoky, N.S.; Setzer, W.N. Chemical composition and biological activities of essential oils of Curcuma species. Nutrients 2018, 10, 1196. [CrossRef] [PubMed]

54. Akarchariya, N.; Sirilun, S.; Julsrigival, J.; Chansakaowa, S. Chemical profiling and antimicrobial activity of essential oil from Curcuma aeruginosa Roxb., Curcuma glans K. Larsen \& J. Mood and Curcuma cf. xanthorrhizaRoxb. collected in Thailand. Asian Pac. J. Trop. Biomed. 2017, 7, 881-885.

55. Roy, A.; Bulut, O.; Some, S.; Mandal, A.K.; Yilmaz, M.D. Green synthesis of silver nanoparticles: Biomolecule-nanoparticle organizations targeting antimicrobial activity. RSC Adv. 2019, 9, 2673-2702. [CrossRef]

56. Gurunathan, S.; Han, J.W.; Kwon, D.-N.; Kim, J.-H. Enhanced antibacterial and anti-biofilm activities of silver nanoparticles against Gram-negative and Gram-positive bacteria. Nanoscale Res. Lett. 2014, 9, 373. [CrossRef]

57. Sahayaraj, K.; Rajesh, S. Bionanoparticles: Synthesis and antimicrobial applications. Sci. Microb. Pathog. Commun. Curr. Res. Technol. Adv. 2011, 23, 228-244.

58. Beddy, D.; Watson, R.; Fitzpatrick, J.; O'connell, P. Increased vascular endothelial growth factor production in fibroblasts isolated from strictures in patients with Crohn's disease. Br. J. Surg. 2004, 91, 72-77. [CrossRef]

59. Mondal, N.K.; Chowdhury, A.; Dey, U.; Mukhopadhya, P.; Chatterjee, S.; Das, K.; Datta, J.K. Green synthesis of silver nanoparticles and its application for mosquito control. Asian Pac. J. Trop. Dis. 2014, 4, S204-S210. [CrossRef]

60. Tian, J.; Wong, K.K.; Ho, C.M.; Lok, C.N.; Yu, W.Y.; Che, C.M.; Tam, P.K. Topical delivery of silver nanoparticles promotes wound healing. ChemMedChem 2007, 2, 129-136. [CrossRef]

61. Liu, X.; Lee, P.Y.; Ho, C.M.; Lui, V.C.; Chen, Y.; Che, C.M.; Wong, K.K. Silver nanoparticles mediate differential responses in keratinocytes and fibroblasts during skin wound healing. ChemMedChem 2010, 5, 468-475. [CrossRef] [PubMed]

62. Vivek, R.; Thangam, R.; Muthuchelian, K.; Gunasekaran, P.; Kaveri, K.; Kannan, S. Green biosynthesis of silver nanoparticles from Annona squamosa leaf extract and its in vitro cytotoxic effect on MCF-7 cells. Process.Biochem. 2012, 47, 2405-2410. [CrossRef] 
63. Paladini, F.; Pollini, M. Antimicrobial Silver Nanoparticles for Wound Healing Application: Progress and Future Trends. Materials 2019, 12, 2540. [CrossRef] [PubMed]

64. Keat, C.L.; Aziz, A.; Eid, A.M.; Elmarzugi, N.A. Biosynthesis of nanoparticles and silver nanoparticles. Bioresour. Bioprocess. 2015, 2, 1-11. [CrossRef]

65. Sulaiman, G.M.; Mohammed, W.H.; Marzoog, T.R.; Al-Amiery, A.A.A.; Kadhum, A.A.H.; Mohamad, A.B. Green synthesis, antimicrobial and cytotoxic effects of silver nanoparticles using Eucalyptus chapmaniana leaves extract. Asian Pac. J. Trop. Biomed. 2013, 3, 58-63. [CrossRef]

66. Das, B.; Dash, S.K.; Mandal, D.; Ghosh, T.; Chattopadhyay, S.; Tripathy, S.; Roy, S. Green synthesized silver nanoparticles destroy multidrug-resistant bacteria via reactive oxygen species mediated membrane damage. Arab. J. Chem. 2017, 10, 862-876. [CrossRef]

67. Chattopadhyay, S.; Chakraborty, S.; Laha, D.; Baral, R.; Pramanik, P.; Roy, S. Surface-modified cobalt oxide nanoparticles: New opportunities for anti-cancer drug development. Cancer Nanotechnol. 2012, 3, 13. [CrossRef]

68. Srivastava, S.; Somasagara, R.R.; Hegde, M.; Nishana, M.; Tadi, S.K.; Srivastava, M.; Raghavan, S.C. Quercetin, a Natural Flavonoid Interacts with DNA, Arrests Cell Cycle and Causes Tumor Regression by Activating Mitochondrial Pathway of Apoptosis. Sci. Rep. 2016, 6, 24049. [CrossRef]

Publisher's Note: MDPI stays neutral with regard to jurisdictional claims in published maps and institutional affiliations.

(C) 2020 by the authors. Licensee MDPI, Basel, Switzerland. This article is an open access article distributed under the terms and conditions of the Creative Commons Attribution (CC BY) license (http://creativecommons.org/licenses/by/4.0/). 